Keywords: $I S D$

Reactor

Retention: Permanent

\title{
Evaluation of the Durability of the Structural Concrete of Reactor Buildings at SRS
}

\author{
A.J. Duncan \\ M.M. Reigel
}

February 2011

Savannah River National Laboratory Savannah River Nuclear Solutions Aiken, SC 29808

Prepared for the U.S. Department of Energy under contract number DE-AC09-08SR22470.

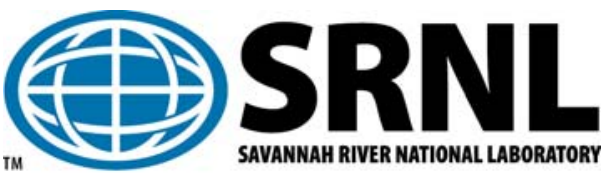


SRNL-STI-2010-00729

Revision 0

\section{DISCLAIMER}

This work was prepared under an agreement with and funded by the U.S. Government. Neither the U.S. Government or its employees, nor any of its contractors, subcontractors or their employees, makes any express or implied:

1. warranty or assumes any legal liability for the accuracy, completeness, or for the use or results of such use of any information, product, or process disclosed; or

2. representation that such use or results of such use would not infringe privately owned rights; or

3. endorsement or recommendation of any specifically identified commercial product, process, or service.

Any views and opinions of authors expressed in this work do not necessarily state or reflect those of the United States Government, or its contractors, or subcontractors.

\section{Printed in the United States of America}

Prepared for

U.S. Department of Energy 


\section{REVIEWS AND APPROVALS}

AUTHORS:

A.J. Duncan, Materials Application \& Process Technology

Date

M.M. Reigel, Engineering Process Development

Date

TECHNICAL REVIEW:

A.D. Cozzi, Engineering Process Development

Date

APPROVAL:

K.E. Zeigler, Manager

Date

Materials Performance and Corrosion Technology

A.B. Barnes, Manager

Date

Engineering Process Development

R.J. Abitz, Technology Program Manager

Environmental Analysis

Date

S.L. Marra, Manager

Date

Environmental \& Chemical Process Technology Research Programs

N.C. Iyer, Manager

Date

Materials Science \& Technology 
SRNL-STI-2010-00729

Revision 0

\section{EXECUTIVE SUMMARY}

The Department of Energy (DOE) intends to close 100-150 facilities in the DOE complex using an in situ decommissioning (ISD) strategy that calls for grouting the below-grade interior volume of the structure and leaving the above-grade interior open or demolishing it and disposing of it in the slit trenches in E Area. These closures are expected to persist and remain stable for centuries, but there are neither facility-specific monitoring approaches nor studies on the rate of deterioration of the materials used in the original construction or on the ISD components added during closure (caps, sloped roofs, etc). This report will focus on the evaluation of the actual aging/degradation of the materials of construction used in the ISD structures at Savannah River Site (SRS) above grade, specifically P \& R reactor buildings.

Concrete blocks (six 2 to 5 ton blocks) removed from the outer wall of the P Reactor Building were turned over to SRNL as the first source for concrete cores. Larger cores were received as a result of grouting activities in $\mathrm{P}$ and $\mathrm{R}$ reactor facilities. The cores were sectioned and evaluated using microscopy, x-ray diffraction (XRD), ion chromatography (IC) and thermal analysis. Scanning electron microscopy shows that the aggregate and cement phases present in the concrete are consistent with the mix design and no degradation mechanisms are evident at the aggregatecement interfaces. Samples of the cores were digested and analyzed for chloride ingress as well as sulfate attack. The concentrations of chloride and sulfate ions did not exceed the limits of the mix design and there is no indication of any degradation due to these mechanisms.

Thermal analysis on samples taken along the longitudinal axis of the cores show that there is a 1 inch carbonation layer (i.e., no portlandite) present in the interior wall of the reactor building and a negligible carbonation layer in the exterior wall. A mixed layer of carbonate and portlandite extends deeper into the interior (2-3 inches) and exterior (1-2 inches) walls. This is more extensive than measured in previous SRS structures ${ }^{1}$.

Once the completely carbonated layer reaches the rebar that is approximately 2-3 inches into the concrete wall, the steel is susceptible to corrosion. The growth rate of the carbonated layer was estimated from current observations and previous studies. Based on the estimated carbonation rate, the steel rebar should be protected from carbonation induced corrosion for at least another 100 years. If degradation of these structures is dominated by the carbonation mechanism, the length of time before water intrusion is expected into the process room of P-reactor is estimated to be between $425-675$ years. 


\section{TABLE OF CONTENTS}

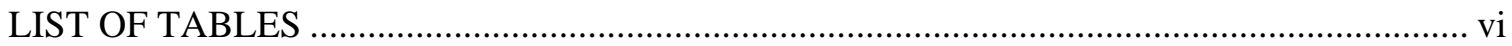

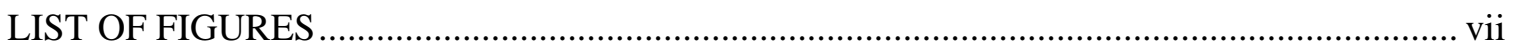

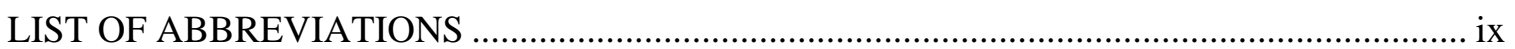

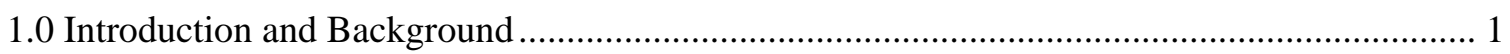

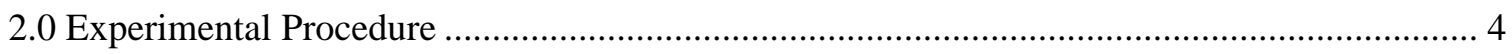

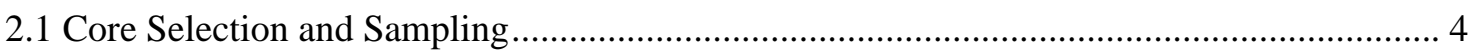

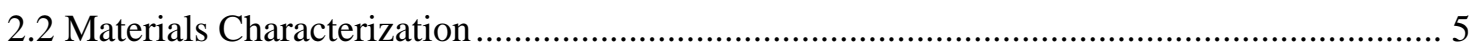

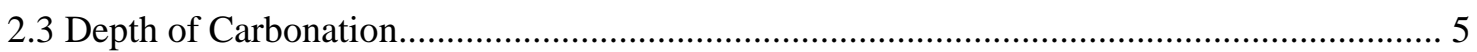

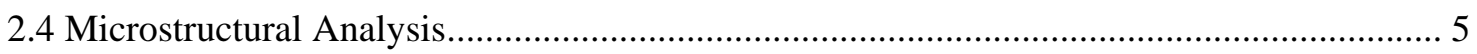

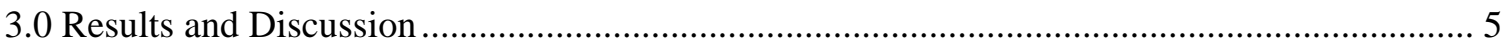

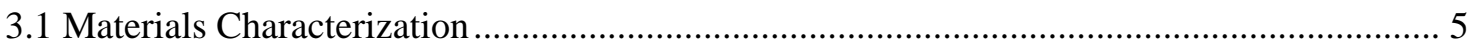

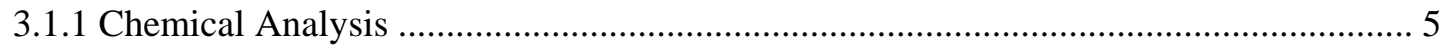

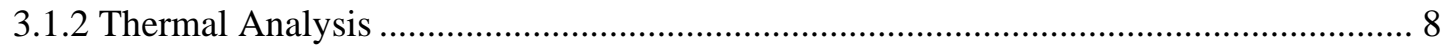

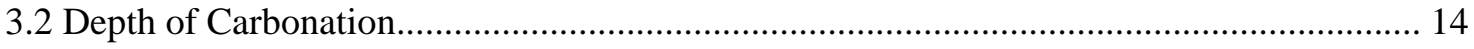

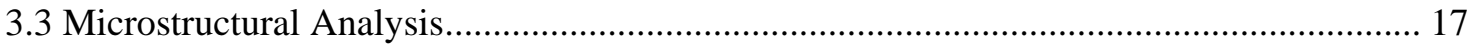

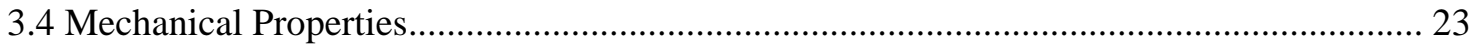

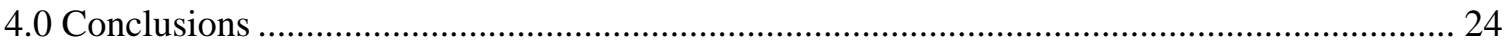

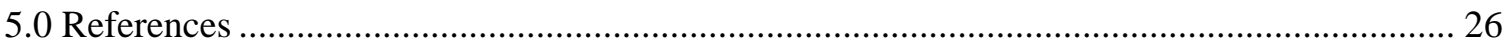

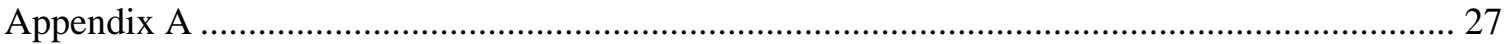




\section{LIST OF TABLES}

Table 1-1. Engineering Specification and Codes and Standards that controlled construction of Reactor Building at SRS. ${ }^{2}$

Table 3-1. ICP-ES data for concrete core samples taken from concrete blocks............................ 6

Table 3-2. Mass loss as a function of depth for the exterior core sample. …................................ 10

Table 3-3. Mass loss as a function of depth for the interior core sample..................................... 13

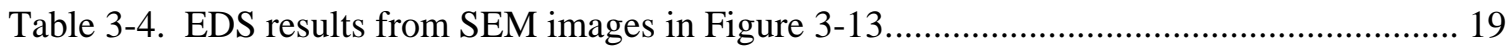

Table 3-5. EDS results from SEM images in Figure 3-14......................................................... 20 
SRNL-STI-2010-00729

Revision 0

\section{LIST OF FIGURES}

Figure 1-1. Aerial photograph of P-Reactor.

Figure 2-1. Concrete blocks removed from the outer wall of the P Reactor Building with location of wall shown (inset).

Figure 3-1. Sulfate and chloride concentration in the interior core sample as a function of depth (horizontal lines are maximum composition expected by mix design estimates)...... 7

Figure 3-2. Sulfate and chloride concentration in the exterior core sample as a function of depth (horizontal lines are maximum composition expected by mix design estimates)................... 7

Figure 3-3. DSC curves for depth samples taken from the exterior core sample......................... 9

Figure 3-4. TGA curves for depth samples taken from the exterior core sample......................... 10

Figure 3-5. DSC curves for depth samples taken from the interior core sample.......................... 12

Figure 3-6. TG curves for depth samples taken from the interior core sample............................ 13

Figure 3-7. Field test of interior core from floor section of corridor 4 in P-reactor...................... 14

Figure 3-8. Field Test of (a) interior and (b) exterior core sections from a wall in disassembly

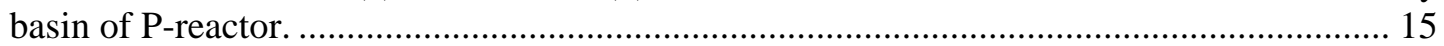

Figure 3-9. Cross section of 3.7” core from interior wall section in disassembly basin of P-reactor with phenolphthalein solution indicating carbonation level of $~ 1.4 "$. ................................. 15

Figure 3-10. Plot of carbonation measurements for P-reactor interior specimens relative to other

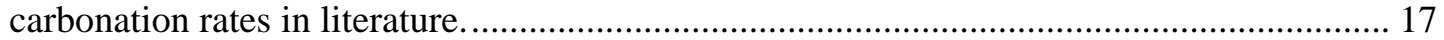

Figure 3-11. Macrograph of concrete core sample from R-reactor.......................................... 17

Figure 3-12. Macrograph of concrete core sample from P-reactor. ........................................... 18

Figure 3-13. BSE Micrograph for granite aggregate in P-reactor concrete showing compositions consistent with (a) fluorapatite, (b) potassium feldspar, and (c) plagioclase feldspar. ........... 19

Figure 3-14. BSE micrograph for (a) small aggregate and (b) cement phase in P-reactor

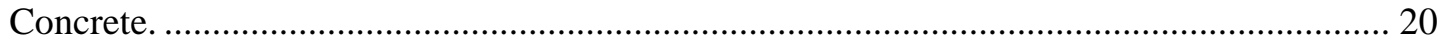

Figure 3-15. XRD scan of pulverized concrete near exterior surface from P-reactor ................... 21

Figure 3-16. XRD scan of pulverized concrete from P-reactor near interior surface.................... 22

Figure 3-17. Compressive strength of concrete cores removed from Reactor buildings at SRS (all cores from P-reactor except \#96)..................................................................................... 23

Figure A-1. DSC Curve for depth samples taken from core 57 taken from R-reactor.................. 28

Figure A-3. TG curve for depth samples from core 57 taken from R-reactor.............................. 29

Figure A-4. DSC curve for depth samples from Corridor \#4 in P-reactor. .................................. 30 
SRNL-STI-2010-00729

Revision 0

Figure A-5. TG curve for depth samples from Corridor \#4 in P-reactor....................................... 31 


\section{LIST OF ABBREVIATIONS}

$\begin{array}{ll}\text { C-S-H } & \text { Calcium Silicate Hydrate } \\ \text { D\&D } & \text { Decommissioning and Deactivation } \\ \text { DSC } & \text { Differential Scanning Calorimetry } \\ \text { DTA } & \text { Differential Thermal Analysis } \\ \text { EDS } & \text { Energy Dispersive Spectroscopy } \\ \text { EXT } & \text { Exterior wall sample } \\ \text { IC } & \text { Ion Chromatography } \\ \text { ICP-ES } & \text { Inductively Coupled Plasma - Emission Spectroscopy } \\ \text { INT } & \text { Interior wall sample } \\ \text { ISD } & \text { In-Situ Decommissioning } \\ \text { ksi } & \text { kilo-pounds per square inch } \\ \text { psi } & \text { pounds per square inch } \\ \text { RH } & \text { Relative Humidity } \\ \text { SEM } & \text { Scanning Electron Microscope } \\ \text { SRNL } & \text { Savannah River National Laboratory } \\ \text { SRS } & \text { Savannah River Site } \\ \text { TGA } & \text { Thermal Gravimetric Analysis } \\ \text { w/c } & \text { water to cement ratio } \\ \text { XRD } & \text { X-Ray Diffraction }\end{array}$




\subsection{Introduction and Background}

The Department of Energy (DOE) is demonstrating the decommissioning of facilities using an in situ decommissioning (ISD) strategy that calls for grouting the below-grade interior volume of the structure and leaving the above-grade interior open and disposing of it in the slit trenches in $\mathrm{E}$ Area. These closures are expected to persist and remain stable for centuries, but there are neither facility-specific monitoring approaches nor studies on the rate of deterioration of the materials used in the original construction or on the ISD components added during closure (caps, sloped roofs, etc). At the Savannah River Site (SRS), a preliminary hierarchy of structures to be evaluated includes:
o P \& R Reactors
o L, K and C Reactors
o Cooling water basins
o F and H Canyons
o Post-1950’s structures

This report will focus on the evaluation of the actual aging/degradation of the materials of construction used in the ISD structures at SRS, specifically P \& R reactor buildings. An initial assessment of the long-term integrity and condition of the P-Reactor reinforced concrete structure (Figure 1-1) was performed in 2008 as an initial evaluation of the effectiveness of potential ISD projects. ${ }^{1}$ The assessment identified possible degradation mechanisms of the concrete such as freeze/thaw, leaching, steel reinforcing corrosion, cracking due to seismic and other loads, vegetative growth, and others. ${ }^{1}$ An estimate of time to water infiltration into the process room due to degradation of the roof slab is between 200 and 1400 years based on different governing assumptions. The lower estimate of 200 years is based on the assumption that roof is left "as is" and no steps are taken to prevent vegetative growth. The upper estimate of 1400 years is based on a 2 step model of concrete carbonation ( 1100 years) and rebar corrosion ( 300 years). 


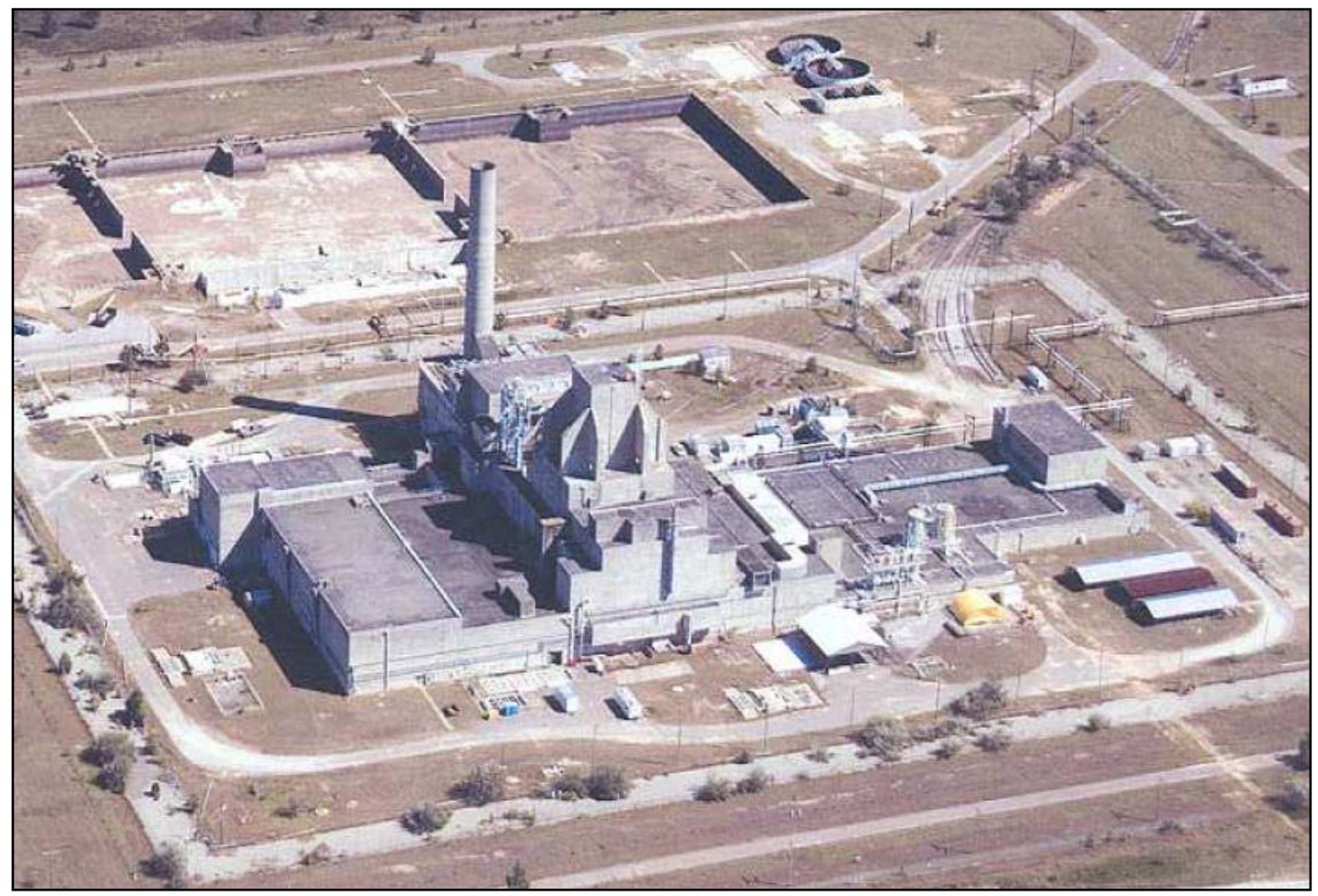

Figure 1-1. Aerial photograph of P-Reactor.

The P-Reactor building was constructed in the early 1950's to Specification 3019, which is broad in scope. The initial concrete mix design called for 2500 psi compression strength within 28 days of placement and reinforcing steel which exhibited a 40,000 psi yield strength. ${ }^{2}$ Table $1-1$ shows the codes and standards that specified the control of materials and methods of construction for the structure. The engineering specification prescribed a minimum cement content for different classes of compression strength. For example, Class D or 2500 psi concrete specified a minimum of $4.4 \mathrm{ft}^{3}$ (or $\sim 430 \mathrm{lbs}$.) per cubic yard of concrete. Cement was generally Type I (normal) or II (moderate sulfate resistance) portland cement (with allowances for use of Type III for circumstances where high early strength was required). Fly ash was allowed (up to $15 \%$ of cement by weight) and a composition was specified consistent with ASTM Class F (designation ASTM C 618). Aggregate was typically quartz sand for fine aggregate ( 0.187 inches $>$ particle diameter $>0.059$ inches) and igneous rock (e.g., granite) for coarse aggregate of diameter up to 1.5 inches (sometimes larger). Admixtures were also allowed for certain applications and airentraining was also permitted. Actual proportions of concrete materials were determined to meet performance requirements in the field (i.e., slump tests). Slump behavior of not more than 3 inches was specified in 3019 but actual slump depended on the design of placement. When specified, water was usually prescribed to yield concrete with a maximum water to cement ratio (w/c) of $\sim 0.63$, although w/c ratio is typically between 0.45 and 0.55 .

In 1996, the Army Corps of Engineers analyzed concrete core and steel rebar samples from Fand H-Canyons at SRS which were built to the same specification as P-reactor. The tests confirmed the design specifications and indicated that although no alkali-silica reaction was occurring, minor carbonation of the concrete was present. ${ }^{3}$ Based on the results of the 1996 and 2008 evaluations of SRS structural concrete buildings, the following degradation mechanisms will be studied in the cores from P \& R Reactor buildings: carbonation, chloride ingress, and rebar corrosion. The existing microstructure of the concrete will also be examined. 
Although reinforcement is an important component for the life of concrete structures, the onset of corrosion of rebar takes place only after the 2-3 inches of concrete cover has fully degraded (usually several hundred years of aging in similar environments). So, as a first step to determining the durability of the structure, the concrete will be the focus of this report.

Table 1-1. Engineering Specification and Codes and Standards that controlled construction of Reactor Building at SRS. ${ }^{2}$

Material
Portland Cement
Aggregate
Water
Reinforcement
Fly Ash
Testing
Proportioning/Batching/Mixing
Placement
Finishing
Curing

Specification

SB-1-A

SB-2-A, 3-A

SB-5-A, 6-A

SB 4-A

3019

SB-5-A

SB-6-A

SB-8-A, 9-A

SB-10-A

SB-11-A
Standard

ASTM C 150

ASTM C 33

AASHTO T26

ASTM A 15, A305 


\subsection{Experimental Procedure}

\subsection{Core Selection and Sampling}

Concrete blocks (six 2 to 5 ton blocks) removed from the outer wall of the P Reactor Building (Figure 2-1) were transferred to SRNL as the first source for concrete cores. Additional concrete cores were obtained from the $\mathrm{P}$ and $\mathrm{R}$ Reactor Buildings when Decommissioning and Deactivation (D\&D) operations drilled through concrete walls and floors to install grout slick lines. Selected sample locations for the blocks were surveyed to determine the rebar locations. Four-inch diameter cores were extracted from the exterior (EXT) and interior (INT) wall surfaces. The cores were at least 18 inches in length and perpendicular to the respective surface. Cores were placed in plastic bags and shipped to Savannah River National Laboratory (SRNL). The cores were cut into two 9-inch lengths, with the interior portion of each core used for compressive strength testing. The outer 9 inches of each core were used for chemical tests and microscopic characterization. Some sections were archived for future study after cleaning and holding in level B storage. Cores (6 inch diameter) were received from D\&D and examined for suitable sampling and sectioned for analysis and characterization.

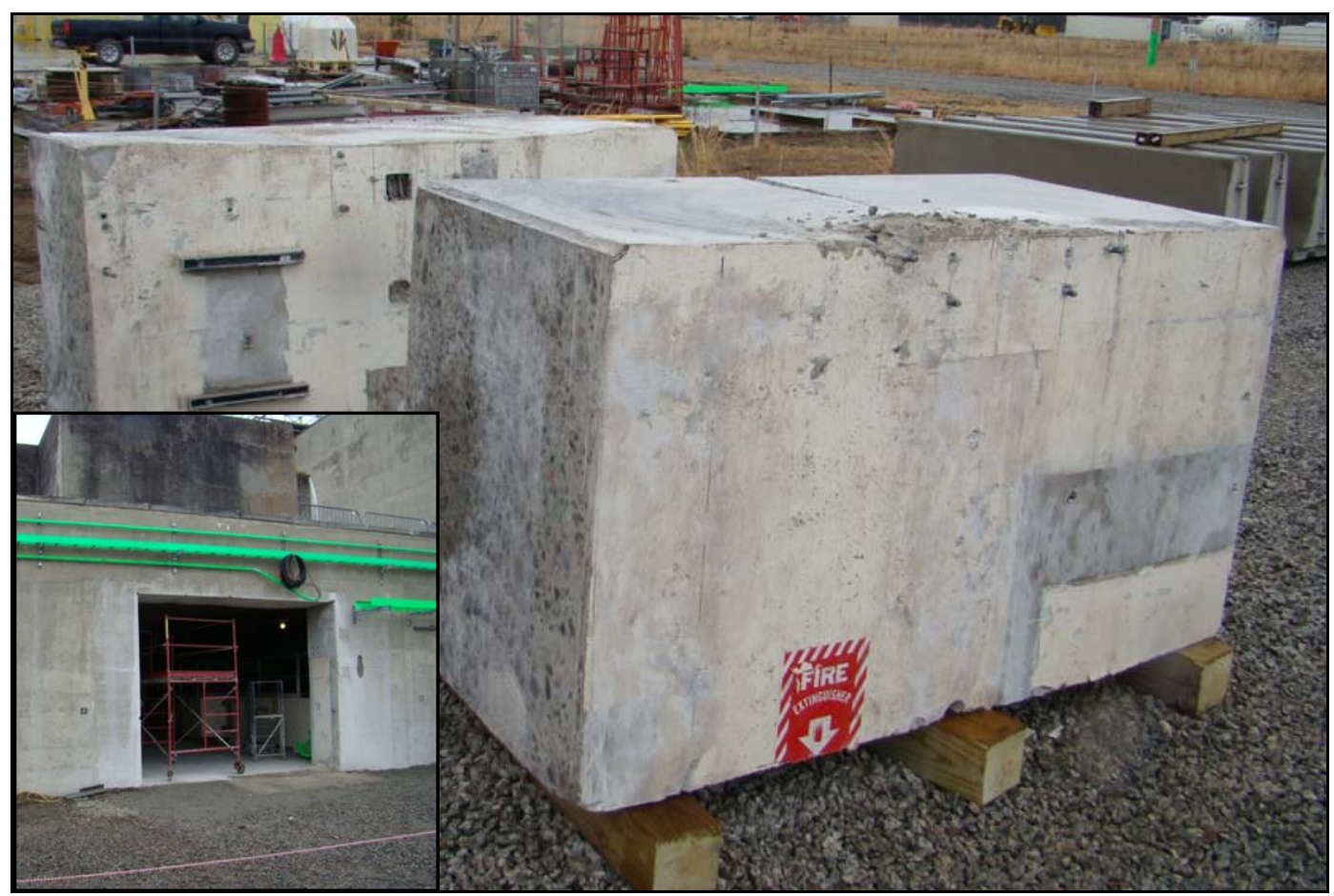

Figure 2-1. Concrete blocks removed from the outer wall of the P Reactor Building with location of wall shown (inset).

Small samples, referred to as "depth samples" were taken from the longitudinal sections to determine any phase and chemical composition change from the wall surface into the center of the concrete wall. The first sample was taken one half inch from below the surface with subsequent samples taken at various depths within the interior to a depth of up to 6 inches. 


\subsection{Materials Characterization}

The depth samples were pulverized and were analyzed by X-ray Diffraction (XRD), Differential Thermal Analysis (DTA), Scanning Electron Microscopy (SEM) with Energy Dispersive Spectroscopy (EDS), and Inductively Coupled Plasma - Emission Spectroscopy (ICP-ES). Splits for ICP-ES were dissolved and analyzed to identify the elements and then calculate the oxides present in the concrete. Anion concentrations were completely dissolved and analyzed for chloride and sulfate ions using ion chromatography (IC) using potassium hydroxide fusion. Thermogravimetric analysis (TGA) was performed to determine the water and carbon dioxide content of each sample. A Netzsch STA 409 Luxx, which couples Differential Scanning Calorimetry (DSC) with Thermal Gravimetric Analysis (TGA), was used for DTA of the core samples. Samples were heated at $10{ }^{\circ} \mathrm{C} / \mathrm{min}$ up to $1000{ }^{\circ} \mathrm{C}$ in a flowing nitrogen atmosphere. Uncertainty of chemical analysis is routinely $\pm 20 \%$ of the value.

\subsection{Depth of Carbonation}

Depth of carbonation was measured on core samples using an acid-base indicator solution. The solution of $1 \%$ phenolphthalein and isopropyl alcohol was applied to a newly exposed crosssectioned surface of the cores. ${ }^{4}$ the solution remains pink if the sample is unaffected by carbonation; the concrete does not change color if there is carbonation of cement phases present. The $\mathrm{pH}$ and chemical composition of the concrete can be estimated based on the color of the solution after it has been applied to the concrete. ${ }^{4}$ These results were used with the DTA measurements to estimate the rate of carbonation of the reactor building walls and access the susceptibility of the steel reinforcement to corrosion from the carbonation front.

\subsection{Microstructural Analysis}

The aggregates of the concrete were examined visually and using SEM. SEM micrographs of the core samples were prepared and analyzed to determine the microstructure of the concrete and EDS was used to determine the distribution of constituent phases present in aggregate and cement phases throughout the sample. Both polished samples and fracture surfaces were examined.

\subsection{Results and Discussion}

\subsection{Materials Characterization}

\subsubsection{Chemical Analysis}

Pieces of the interior cores as well as the exterior cores were pulverized into a fine powder. A portion of the powder from each sample was then dissolved by both acid digestion and sodium peroxide fusion. The composition was determined using inductively coupled plasma spectroscopy emission spectroscopy (ICP-ES). The oxygen content is determined by assuming the most stable compound stoichiometry for each oxide. ICP-ES is not sensitive to hydrogen, carbon or sulfur. Therefore mass balances do not add up to $100 \%$. The concentration of alumina and calcia is about half of what would be expected from concrete with specified amount of portland cement ( $4.4 \mathrm{cu}$. ft./ cu. y) and richer in silica which would indicate the presence of fly ash in the mix (Table 3-1). 
Table 3-1. ICP-ES data for concrete core samples taken from concrete blocks (wt. \%).

\begin{tabular}{|c|c|c|c|c|c|}
\hline Constituent & $\begin{array}{c}\text { B1S INT } \\
(\%) \\
\end{array}$ & $\begin{array}{c}\text { B1N EXT } \\
(\%)\end{array}$ & $\begin{array}{c}\text { B2S INT } \\
(\%)\end{array}$ & $\begin{array}{c}\text { B2S EXT } \\
(\%)\end{array}$ & $\begin{array}{c}\text { Average } \\
(\%)\end{array}$ \\
\hline $\mathrm{Al}_{2} \mathrm{O}_{3}$ & 2.90 & 3.83 & 2.27 & 4.90 & 3.47 \\
\hline $\mathbf{B}_{2} \mathbf{O}_{3}$ & 0.16 & 0.11 & 0.09 & 0.22 & 0.15 \\
\hline $\mathrm{CaO}$ & 7.06 & 3.78 & 3.10 & 3.06 & 4.25 \\
\hline $\mathrm{CdO}$ & 0.01 & 0.02 & 0.00 & 0.03 & 0.02 \\
\hline $\mathrm{CeO}_{2}$ & 0.04 & 0.04 & 0.04 & 0.04 & 0.04 \\
\hline $\mathrm{Cr}_{2} \mathrm{O}_{3}$ & 0.22 & 0.40 & 0.02 & 0.47 & 0.28 \\
\hline $\mathrm{Cu}_{2} \mathrm{O}$ & 0.03 & 0.03 & 0.05 & 0.05 & 0.04 \\
\hline $\mathrm{Fe}_{2} \mathrm{O}_{3}$ & 1.21 & 1.02 & 0.76 & 1.28 & 1.07 \\
\hline $\mathrm{K}_{2} \mathrm{O}$ & 0.39 & 1.16 & 0.72 & 1.79 & 1.02 \\
\hline $\mathbf{L i}_{2} \mathbf{O}$ & 0.14 & 0.14 & 0.14 & 0.14 & 0.14 \\
\hline MgO & 0.33 & 0.12 & 0.08 & 0.19 & 0.18 \\
\hline $\mathrm{MnO}_{2}$ & 0.02 & 0.01 & 0.01 & 0.05 & 0.02 \\
\hline $\mathrm{Na}_{2} \mathrm{O}$ & 0.27 & 0.89 & 0.55 & 1.29 & 0.75 \\
\hline $\mathrm{SiO}_{2}$ & 62.06 & 80.23 & 82.32 & 82.15 & 76.69 \\
\hline SrO & 0.02 & 0.00 & 0.00 & 0.00 & 0.00 \\
\hline $\mathrm{TiO}_{2}$ & 0.29 & 0.40 & 0.41 & 0.31 & 0.35 \\
\hline $\mathrm{ZrO}_{2}$ & 0.11 & 0.14 & 0.11 & 0.11 & 0.12 \\
\hline $\mathrm{SO}_{4}$ & $* * *$ & $* * *$ & $* * *$ & $* * *$ & $* * *$ \\
\hline $\mathrm{CO}_{2}$ & $* * *$ & $* * *$ & $* * *$ & $* * *$ & $* * *$ \\
\hline $\mathrm{H}_{2} \mathrm{O}$ & $* * *$ & $* * *$ & $* * *$ & $* * *$ & $* * *$ \\
\hline Total & 75.27 & 92.31 & 90.67 & 96.08 & 88.58 \\
\hline
\end{tabular}

** values not available with cation analysis

The results for the interior and exterior cores are shown in Figure 3-1 and Figure 3-2, respectively. The horizontal lines on each graph represent the maximum amount of chloride or sulfate ions expected in the samples based on the mix design estimates. On Figure 3-1, both the chloride and sulfate ion concentrations are well below the expected concentrations. The concentration of chloride ion is slightly higher at the surface of the core compared to there rest of the depth samples; however this could be due to chemical contamination (e.g., paint) from inside the reactor building. The sulfate concentration in the interior sample remains constant around $1000 \mathrm{mg} / \mathrm{kg}$. The chloride concentrations in the exterior sample (Figure 3-2) are higher than in the interior sample, but are still at or below the expected concentration for the mix design. Sulfate in the exterior sample is at the expected concentration. The difference between the anion concentrations in the exterior and interior is unknown and further study is recommended to determine the cause (if any). 


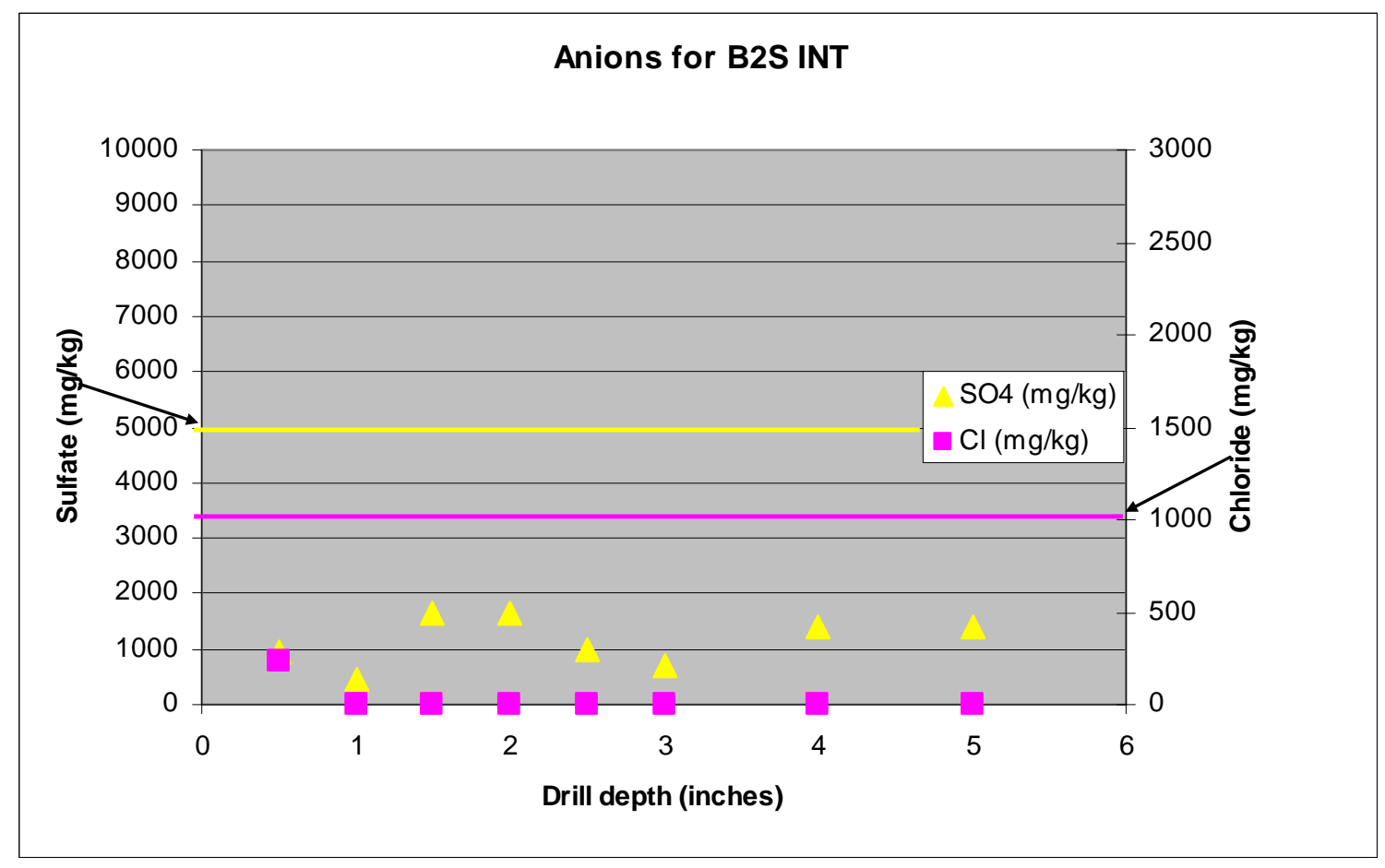

Figure 3-1. Sulfate and chloride concentration in the interior core sample as a function of depth (horizontal lines are maximum composition expected by mix design estimates).

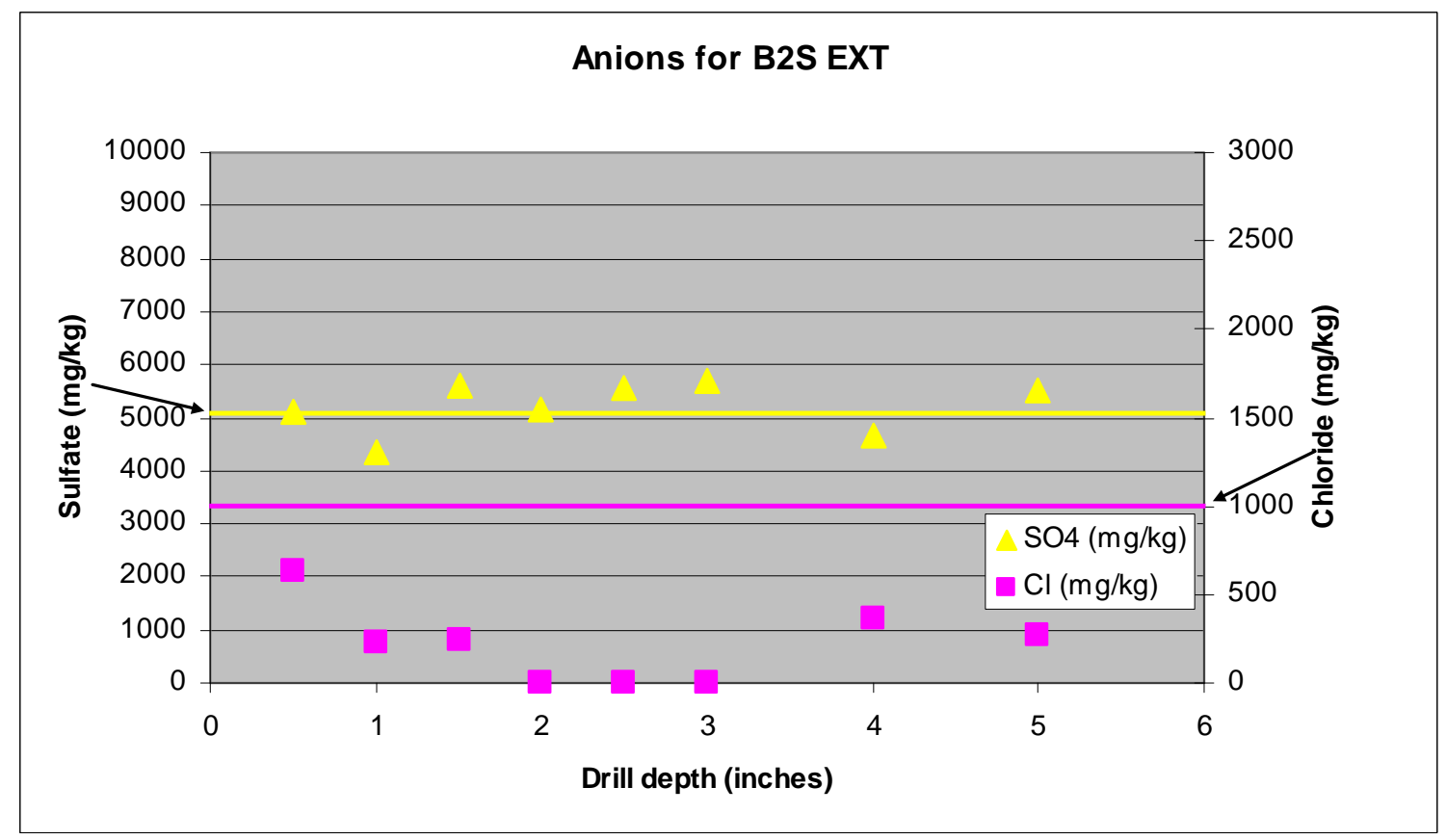

Figure 3-2. Sulfate and chloride concentration in the exterior core sample as a function of depth (horizontal lines are maximum composition expected by mix design estimates). 


\subsubsection{Thermal Analysis}

There are two measurements used to evaluate the data collected from thermal analysis. The mass change (TGA) shown in percent indicates the presence of hydrated or carbonated species in the concrete, and the DSC curve (shown in $\mathrm{mW} / \mathrm{mg}$ ) shows any decomposition corresponding with specific phases in the sample as it is heated (negative values indicate an endothermic reaction and positive values indicate an exothermic reaction). ${ }^{5}$ Multiple literature references have shown that any remaining water in the system will be released between $25-105{ }^{\circ} \mathrm{C}$, followed by the decomposition of concrete phases in the following order: gypsum and ettringite between 100 $170{ }^{\circ} \mathrm{C}$, then some calcium-silica-hydrate phases (C-S-H) between $180-300{ }^{\circ} \mathrm{C}$, dehydroxylation of portlandite from $450-550{ }^{\circ} \mathrm{C}$, other C-S-H phases at $500-700{ }^{\circ} \mathrm{C}$, and decarbonation of calcium carbonate from $700-900{ }^{\circ} \mathrm{C} .^{5-7}$ Another endothermic event at $573{ }^{\circ} \mathrm{C}$ may be visible on the DSC curve and it represents the alpha to beta quartz phase transformation associated with the fine aggregate, which does not have any mass change associated with the trasformation. ${ }^{7}$

Figure 3-3 and Figure 3-4 are the TGA and DSC curves, respectively, of the depth samples taken from the exterior wall core. The DSC curve (Figure 3-3) shows three endothermic events at approximately $50-70,450$, and $700{ }^{\circ} \mathrm{C}$, which correspond to three mass losses on Figure 3-4 at the same temperatures. Thermal events that occur between 50 and $70{ }^{\circ} \mathrm{C}$ are due to the dehydration of the sample. The dehydroxylation of portlandite at $\sim 450{ }^{\circ} \mathrm{C}$ is present in all of the depth samples, although the amount of portlandite in the sample increases with sample depth into the wall (Table 3-2). Decomposition of carbonate at $700{ }^{\circ} \mathrm{C}$ is pronounced in the first two depth samples (B2S-EXT-1 and-2) and evident in the third (B2S-EXT-3). The endothermic carbonation peak at $700{ }^{\circ} \mathrm{C}$ is defined in the first sample, which corresponds to approximately $2 \%$ mass loss in the sample. This indicates that the exterior walls are most carbonated at the surface and slightly carbonated at a depth of 1.5 inches (Figure 3-4 and Table 3-2).

Although there is not a defined endotherm that would indicate the decomposition of the cementitious phases (except portlandite at $\sim 430-450{ }^{\circ} \mathrm{C}$ ), there is a consistent endothermic reaction and mass loss trend in both Figure 3-3 and Figure 3-4, respectively, that is associated with the decomposition of C-S-H and calcium. According to literature, the C-S-H water begins to dissociate around $300{ }^{\circ} \mathrm{C}$. Further dehydration of the cement paste due to decomposition of calcium hydroxide begins about $430{ }^{\circ} \mathrm{C}$, but temperatures on the order of $900{ }^{\circ} \mathrm{C}$ are required for complete decomposition of the C-S-H. ${ }^{8}$ 


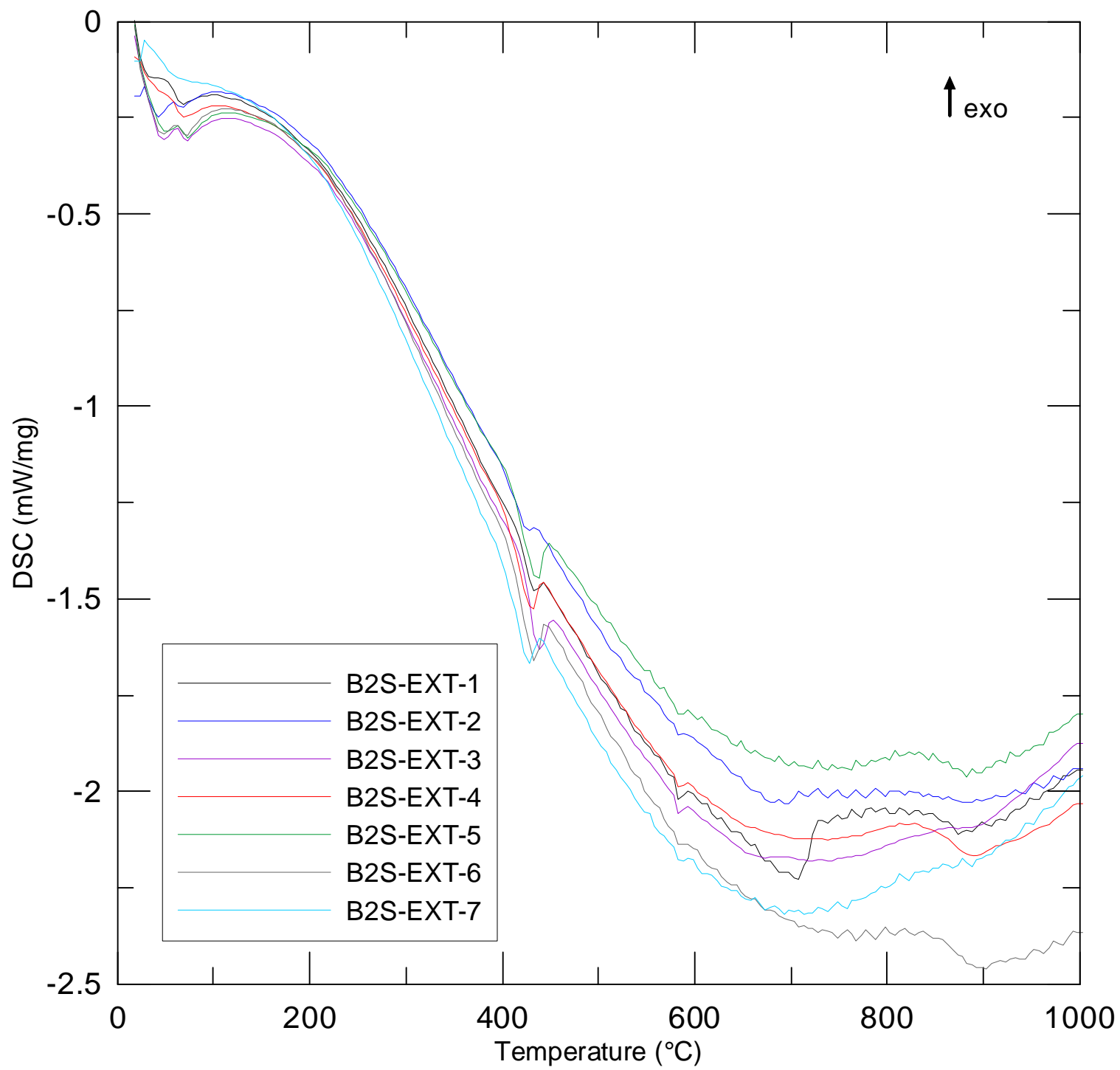

Figure 3-3. DSC curves for depth samples taken from the exterior core sample. 


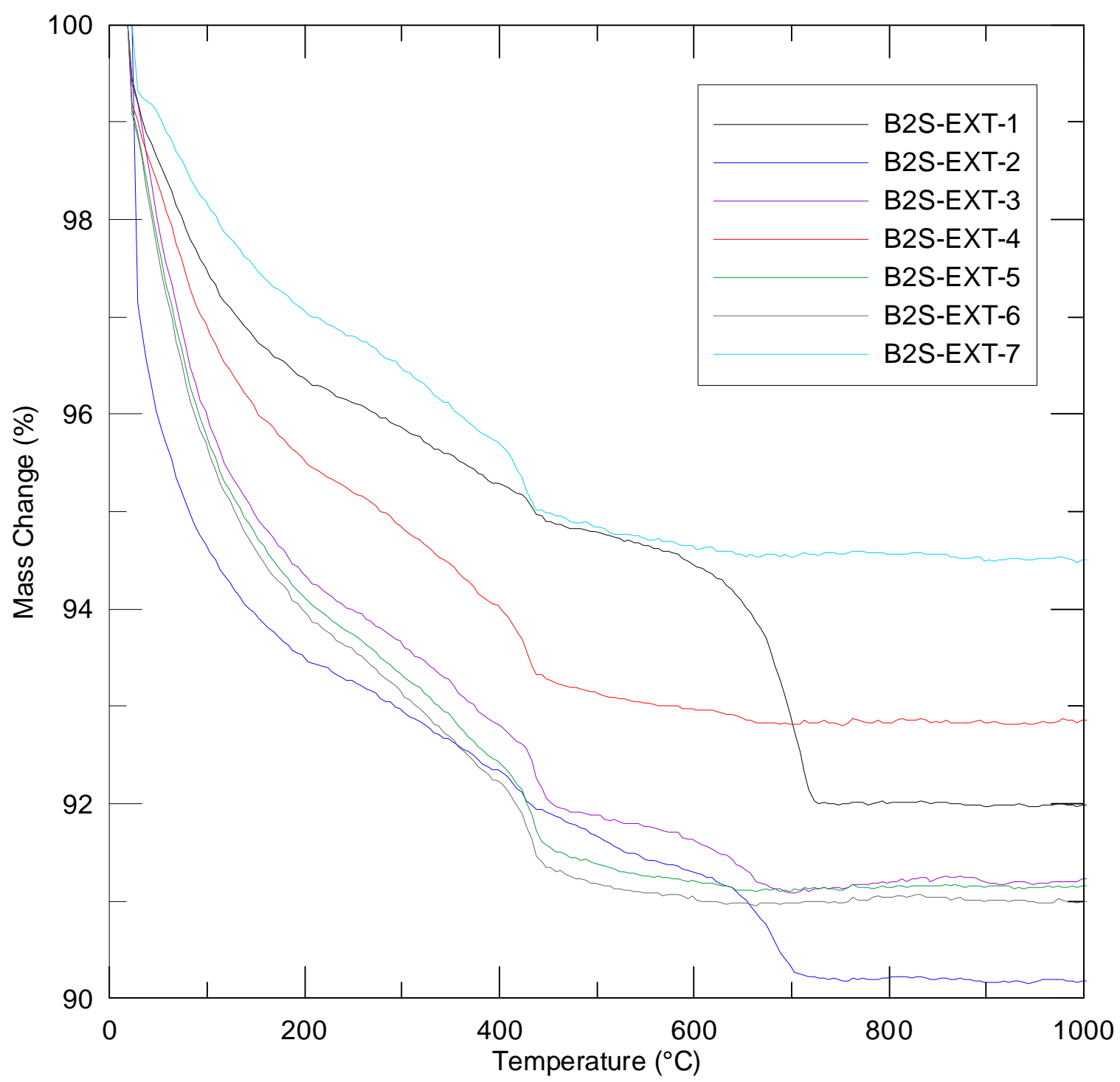

Figure 3-4. TGA curves for depth samples taken from the exterior core sample.

Table 3-2. Mass loss as a function of depth for the exterior core sample.

\begin{tabular}{||c|c|c|c|c|}
\cline { 3 - 5 } \multicolumn{1}{c|}{} & \multicolumn{3}{c|}{ Mass Loss (\%) } \\
\hline \hline Sample & Depth (in) & Water & Portlandite & Carbonate \\
\hline \hline B2S-EXT-1 & 0.5 & 2.56 & 0.31 & 2.53 \\
\hline B2S-EXT-2 & 1 & 3.66 & 0.41 & 1.04 \\
\hline B2S-EXT-3 & 1.5 & 3.75 & 0.88 & 0.36 \\
\hline B2S-EXT-4 & 2 & 2.50 & 0.85 & 0.09 \\
\hline B2S-EXT-5 & 2.5 & 3.66 & 1.09 & N/A \\
\hline B2S-EXT-6 & 3 & 3.78 & 0.99 & N/A \\
\hline B2S-EXT-7 & 4 & 1.77 & 0.88 & N/A \\
\hline
\end{tabular}


Figure 3-5 and Figure 3-6 show the TGA and DSC curves for the depth samples taken from the interior wall core. The two depth samples taken closest to the interior surface have no endothermic event at 70 or $430{ }^{\circ} \mathrm{C}$ and minimal mass loss until above $600{ }^{\circ} \mathrm{C}$ when decomposition of the carbonate begins. There is evidence of carbonate in the samples until approximately 2.5 inches into the core. Portlandite is present in the interior walls except at the surface, which indicates the interior wall is fully carbonated on the order of an inch into the wall. Table 3-3 shows the mass loss associated with each phase decomposition as a function of depth. It should be noted that the further away from the surface, more portlandite and less carbonate is present in the wall.

The endothermic trend corresponding with a gradual mass loss in Figure 3-5 and Figure 3-6 is due to the gradual decomposition of the cementitious phases. This is the same trend as discussed for the exterior samples in Figure 3-3 and Figure 3-4.

Additional cores were taken from Core 57 (R-reactor) and Corridor \#4 (P-Reactor). Depth samples from these cores were analyzed using TGA and DSC. The results are included in Appendix A. 


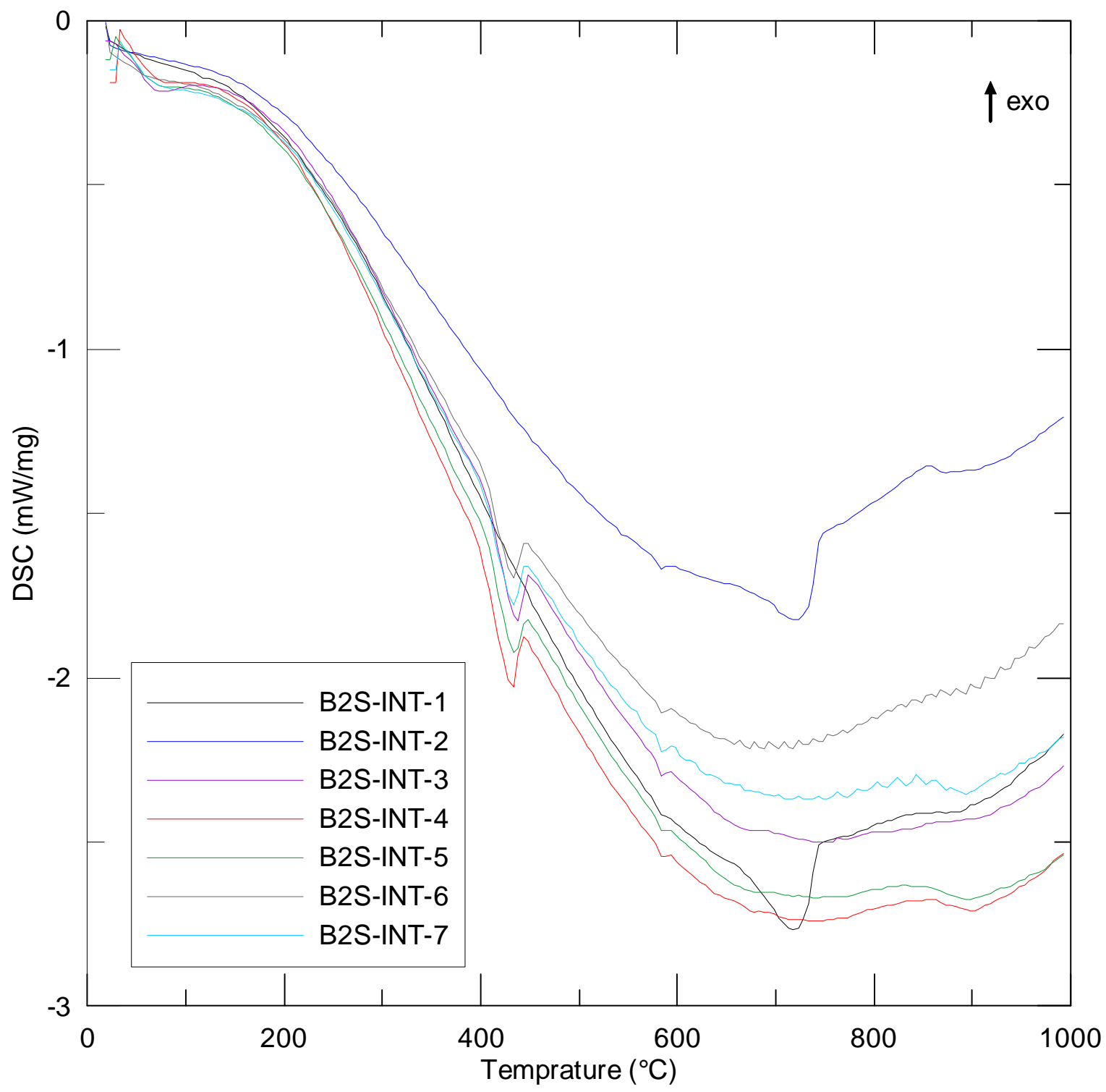

Figure 3-5. DSC curves for depth samples taken from the interior core sample. 


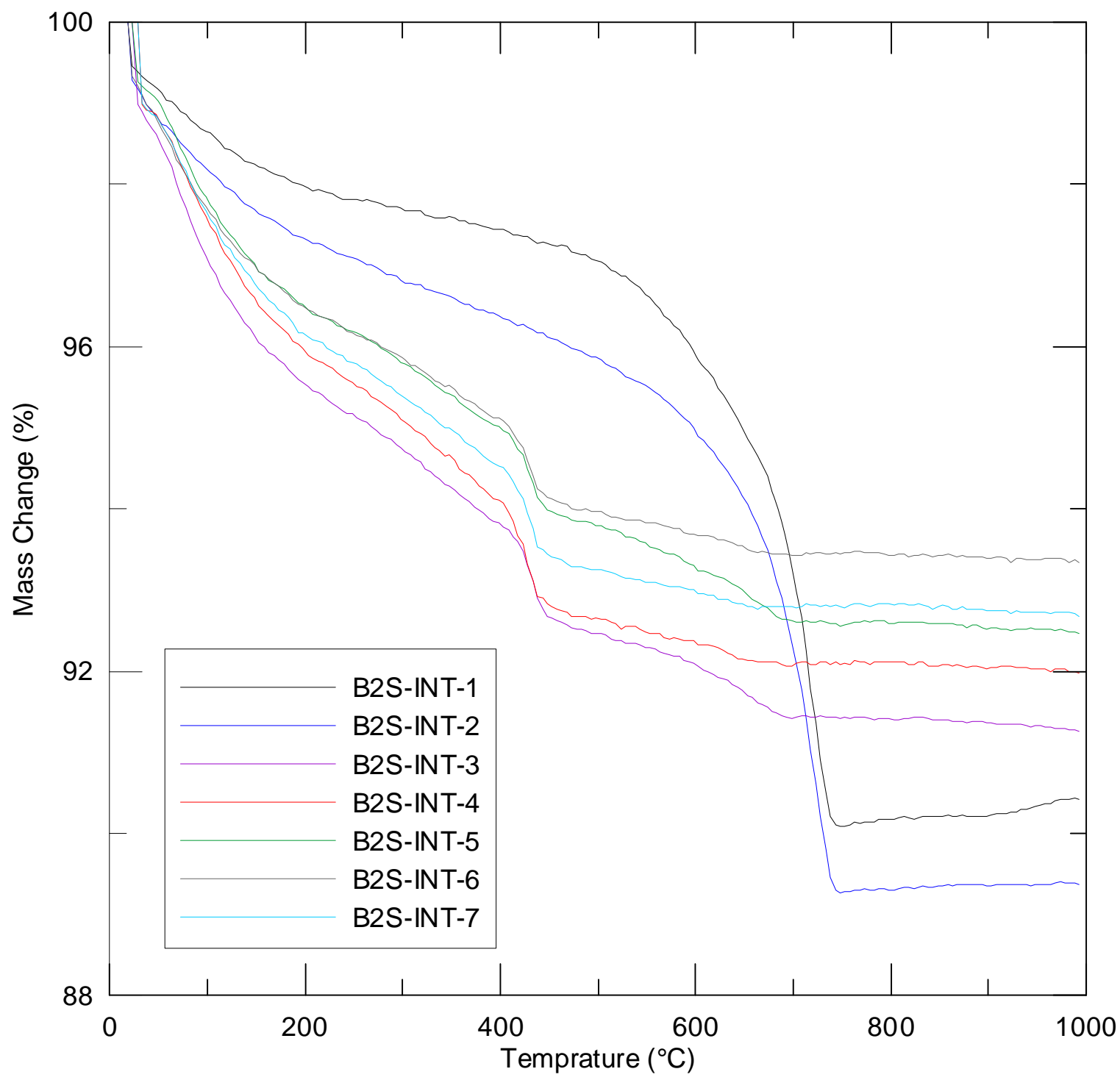

Figure 3-6. TG curves for depth samples taken from the interior core sample.

Table 3-3. Mass loss as a function of depth for the interior core sample.

\begin{tabular}{||c|c|c|c|c||}
\cline { 3 - 5 } \multicolumn{1}{c|}{} & \multicolumn{3}{c||}{ Mass Loss (\%) } \\
\hline Sample & Depth (in) & Water & Portlandite & Carbonate \\
\hline B2S-INT-1 & 0.5 & 0.94 & N/A & 6.71 \\
\hline B2S-INT-2 & 1 & 1.50 & N/A & 6.26 \\
\hline B2S-INT-3 & 1.5 & 2.39 & 1.30 & 0.93 \\
\hline B2S-INT-4 & 2 & 2.44 & 1.46 & 0.28 \\
\hline B2S-INT-5 & 2.5 & 1.60 & 1.20 & 0.62 \\
\hline B2S-INT-6 & 3 & 2.33 & 1.17 & 0.21 \\
\hline B2S-INT-7 & 4 & 1.54 & 1.27 & N/A \\
\hline
\end{tabular}




\subsection{Depth of Carbonation}

Carbonation is the primary cause of long-term degradation in above-grade concrete structures at SRS. Carbon dioxide $\left(\mathrm{CO}_{2}\right)$ diffuses from the surrounding medium and reacts with portlandite and other cement phases to form calcium carbonate, which reduces the concrete $\mathrm{pH}$ from basic to neutral. ${ }^{4,9}$ The high alkaline environment forms a protective thin film around the steel rebar, but when the $\mathrm{pH}$ of the surrounding concrete is lowered by the carbonation reaction, the passive film deteriorates and the reinforcing steel is vulnerable to corrosion. ${ }^{9}$

A qualitative assessment of carbonation is visually determined by applying a $1 \%$ phenolphthalein solution to the concrete sample. When applied to normal concrete, the solution will turn bright pink. If the cement phases have undergone carbonation, no color change will be observed. Hence, the transition from pink to clear represents a $\mathrm{pH}$ boundary where the carbonate has completely replaced the portlandite and a high $\mathrm{pH}$ pore solution is no longer protective to the rebar when moisture is present. Figures 3-7 through 3-9 show various core samples from different locations in P-reactor which have been evaluated for carbonation using the $1 \%$ phenolphthalein solution. This phenolphthalein test supports the results from the thermal analysis of the core samples taken from the concrete blocks. As shown in Figure 3-7 through 3-9, the interior cores have a distinct carbonation layer that is not present in the exterior cores (indicating incomplete carbonation).

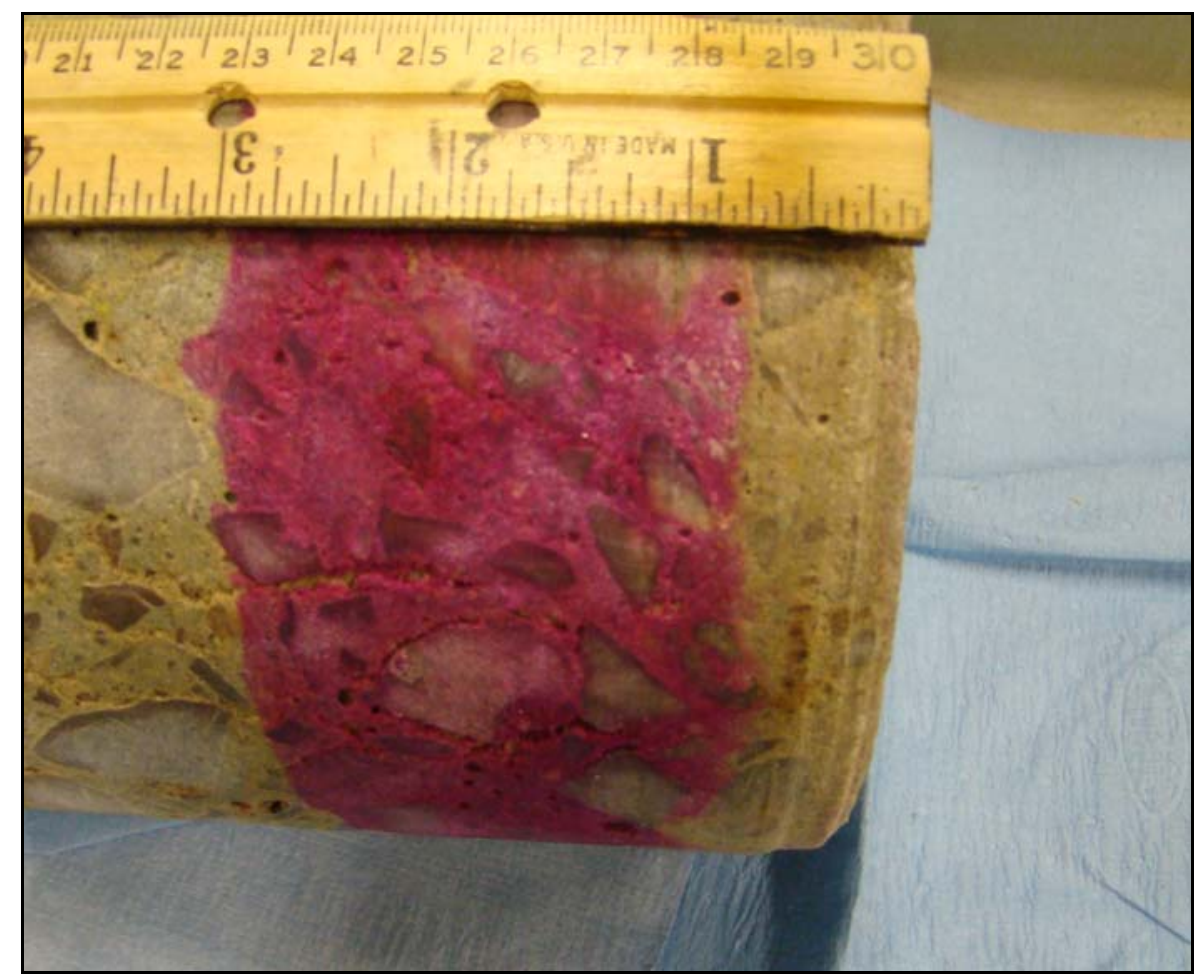

Figure 3-7. Field test of interior core from floor section of corridor 4 in P-reactor. 


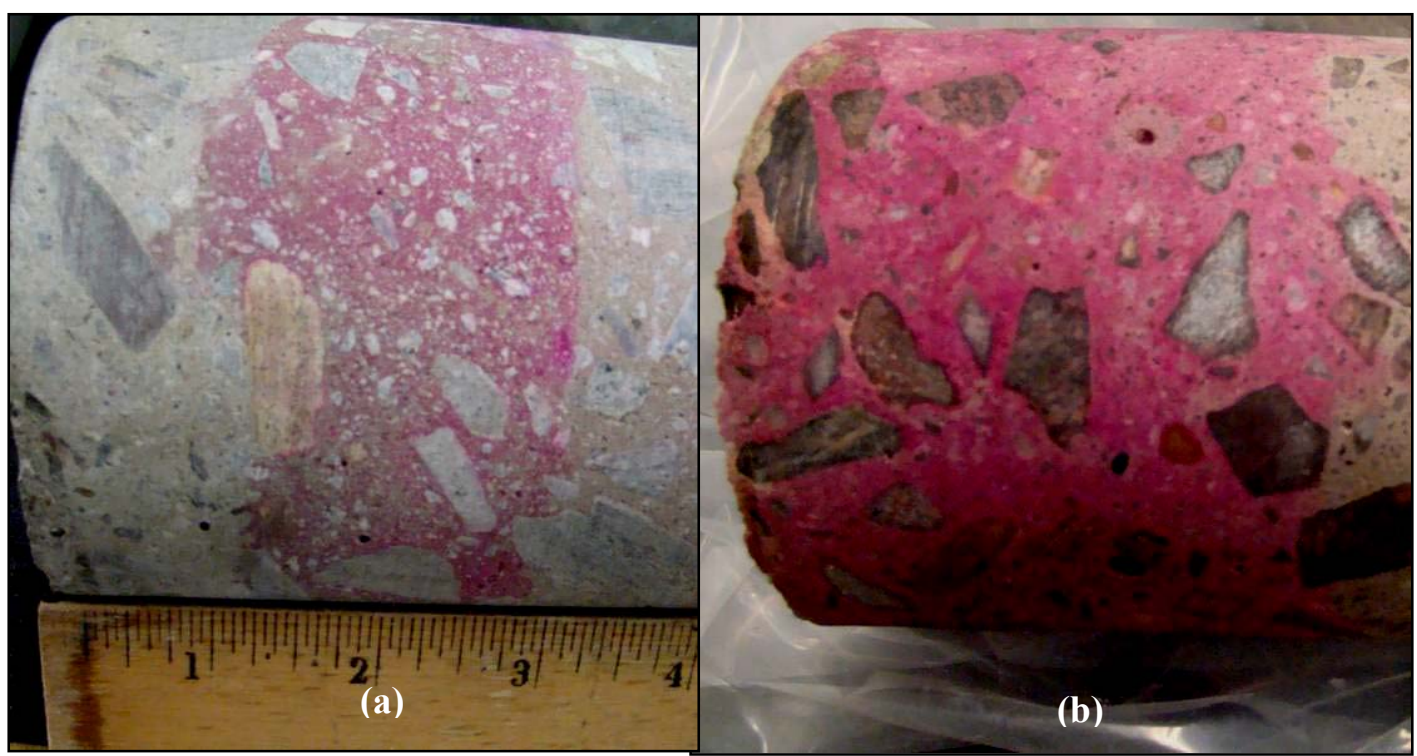

Figure 3-8. Field Test of (a) interior and (b) exterior core sections from a wall in disassembly basin of P-reactor.

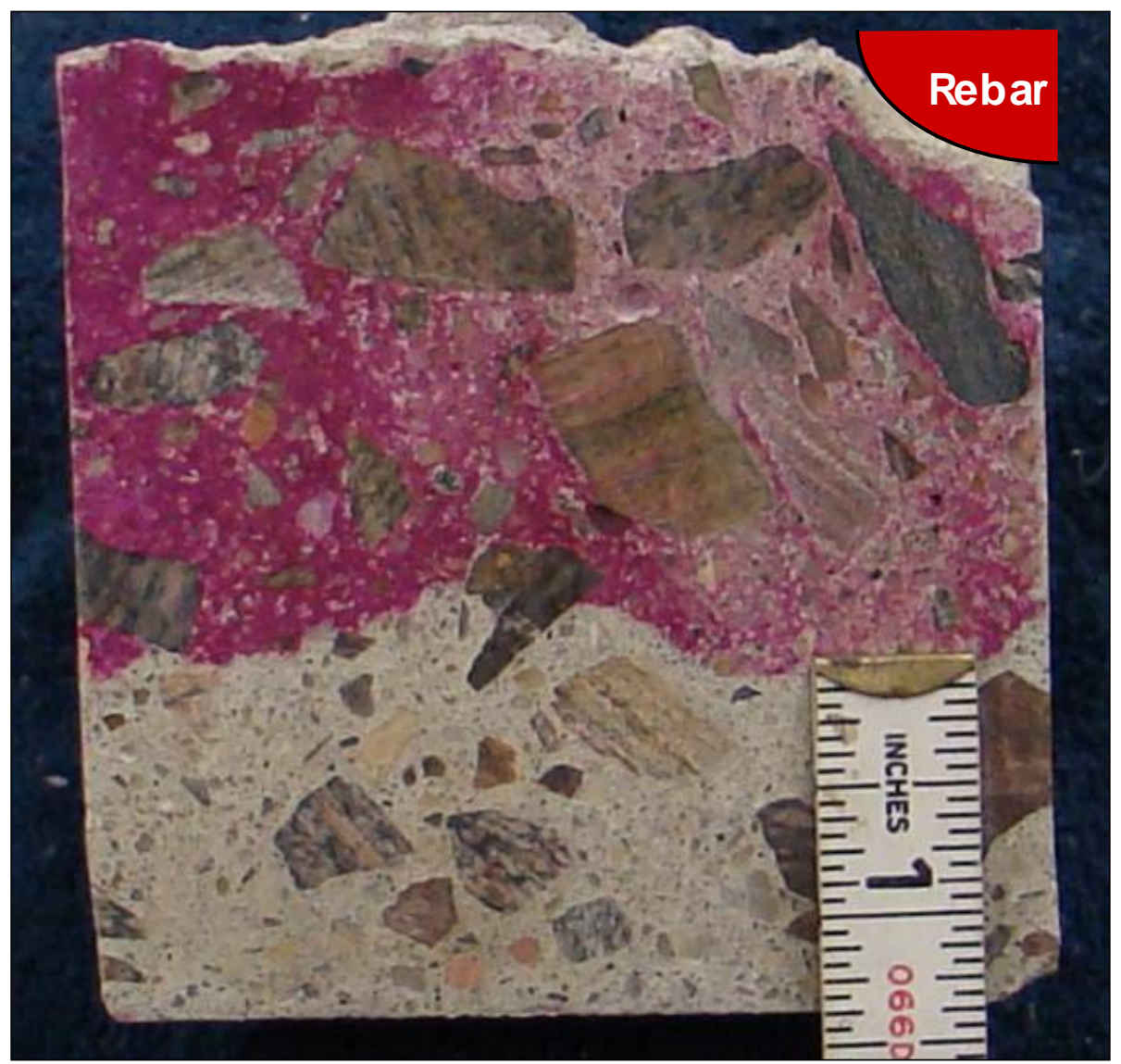

Figure 3-9. Cross section of 3.7" core from interior wall section in disassembly basin of Preactor with phenolphthalein solution indicating carbonation level of $\sim 1.4 "$. 
Many factors can affect the rate of carbonation, including temperature, relative humidity, and composition of the cement paste. Generally, the depth of carbonation is roughly proportional to the square root of time for concrete kept continuously dry at normal relative humidities (RH).

$$
X_{c}=A(t)^{1 / 2}
$$

Where $\mathrm{X}_{\mathrm{c}}$ is the distance of the carbonation front, $\mathrm{t}$ is the time and $\mathrm{A}$ is a materials constant. ${ }^{10}$ Papadakis et al developed an expression for A from theoretical basis. ${ }^{10}$

$$
\mathrm{A}=\sqrt{ } \frac{2\left[\mathrm{CO}_{2}\right]^{0} \mathrm{D}_{\mathrm{eCO} 2}}{\left[\mathrm{Ca}(\mathrm{OH})_{2}(\mathrm{~s})\right]^{0}+3[\mathrm{CSH}]^{0}}
$$

$\mathrm{D}_{\mathrm{eCO} 2}$ is the effective diffusivity of $\mathrm{CO}_{2}$ in the concrete, while $\left[\mathrm{CO}_{2}\right]^{0},\left[\mathrm{Ca}(\mathrm{OH})_{2}(\mathrm{~s})\right]^{0}$ and $[\mathrm{CSH}]^{0}$ are the molar concentrations in the concrete. The effective diffusivity of $\mathrm{CO}_{2}$ is dependent on pore size. The water to cement ratio (w/c) used in the concrete mix design is integral in determining the pore size of the hardened concrete. As RH increases, the pores become saturated with moisture and the effective diffusivity of $\mathrm{CO}_{2}$ is lowered. However, when concrete is kept dry at normal $\mathrm{RH}$, the pores can become unsaturated which allows $\mathrm{CO}_{2}$ to diffuse more rapidly into the concrete. In extreme cases of $\mathrm{RH}$ below $\sim 40 \%$, carbonation rates are hindered by the lack of any physical water adsorbed to the surface of pores. Hence, the carbonation rate is observed to be maximized in conditions typical of indoor service. Figure 3-10 compares the carbonation depth of P-reactor concrete (an average of three different locations measured using the phenolphthalein test) with carbonation depths found in literature for a w/c ratio of 0.52 and 0.48 for indoor service conditions. For 10 years of service the carbonation depths vary for the 2 cases shown between 0.5 and $1 \mathrm{~cm} .{ }^{10}$ Extrapolation of this graph to 60 years of service suggests a lower carbonation rate than measured in Figure 3-9 for P-reactor. The difference may be attributed to different starting mix designs, experimental error and environmental conditions.

The carbonation reaction will continue from the surface toward the center of the concrete wall or slab. As shown in Figure 3-9, there is still a significant buffer zone between the fully carbonated concrete and the structural rebar. Since the carbonation is proportional to the square root of time, the length of time required for the carbonation front to eclipse the remainder of the cover is longer than the time it takes to eclipse the initial portion. Based on the rate equation estimated from the P-reactor field measurements, it will be more than an additional 125 years for the carbonation front to advance beyond the designed 2 inch cover and reach the structural rebar. Although not specified, three inches of cover was observed in the blocks sampled, so using the estimated carbonation rate, it would take 275 years for the carbonation front to span the cover. This estimate of rate is conservative because it assumes that the carbonation front will continue to advance at an accelerated rate due to its exposure to humidity controlled air (i.e., RH $~ 50 \%$ ) throughout the remaining 1-3 centuries.

Once the steel rebar is at risk for corrosion, it will take an unknown number of years to corrode the steel to a point where loss of concrete cover and loss of structural integrity results. In order for corrosion to occur water must be present in abundance and oxygen diffusion can limit the rate of corrosion. Further study is needed to determine an estimate of corrosion rates of the structural rebar in the walls of P and R-reactors after the carbonation front has reached the concrete/rebar interface. 


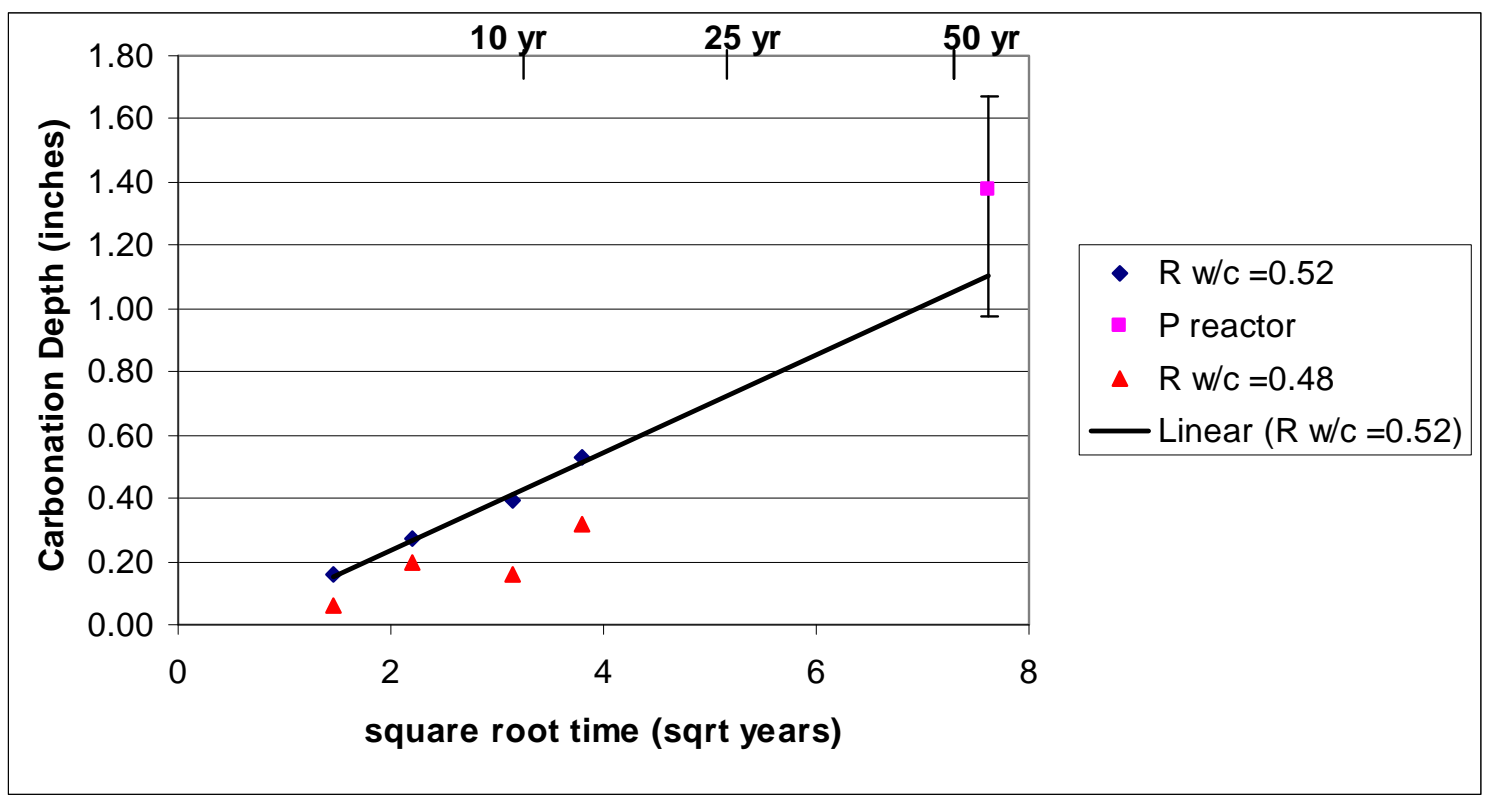

Figure 3-10. Plot of carbonation measurements for P-reactor interior specimens relative to other carbonation rates in literature.

\subsection{Microstructural Analysis}

The concrete cores were analyzed visually and using macro-photography, optical microscopy and SEM to determine the phases present in the concrete and any obvious degradation mechanisms occurring. Figure 3-11 and Figure 3-12 are macrographs of a cross section of a core from Rreactor and P-reactor, respectively. The cores are intact with limited microcracks present that may be due to the coring process or to sectioning the cores. There does not appear to be any detrimental interactions at the cement-aggregate interface.

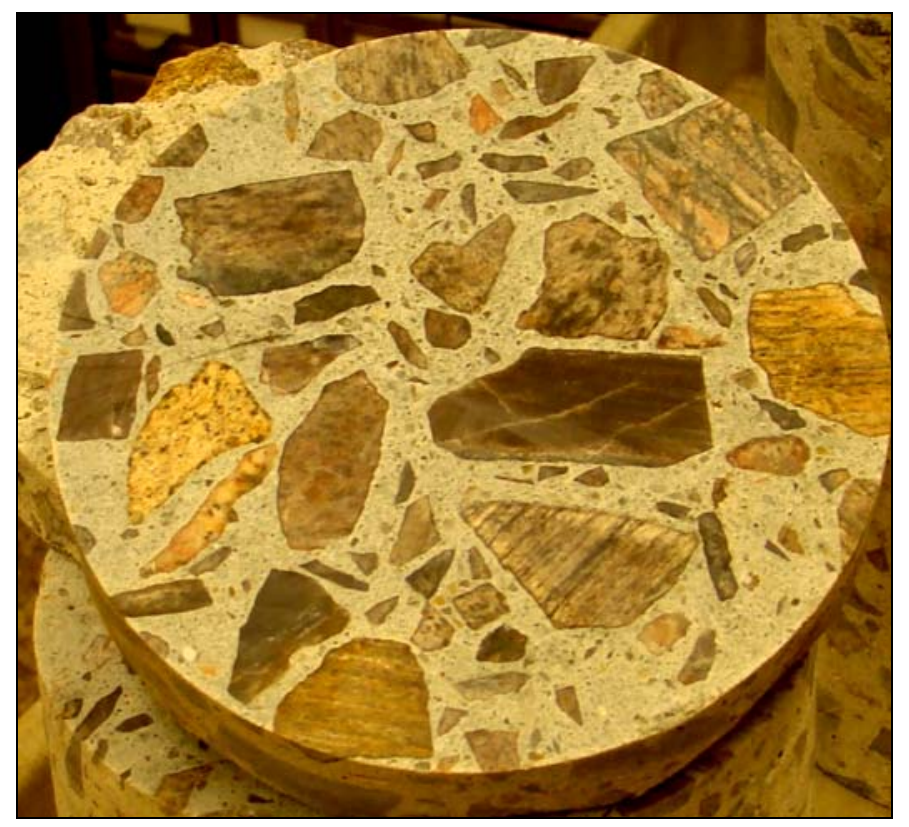

Figure 3-11. Macrograph of concrete core sample from R-reactor. 


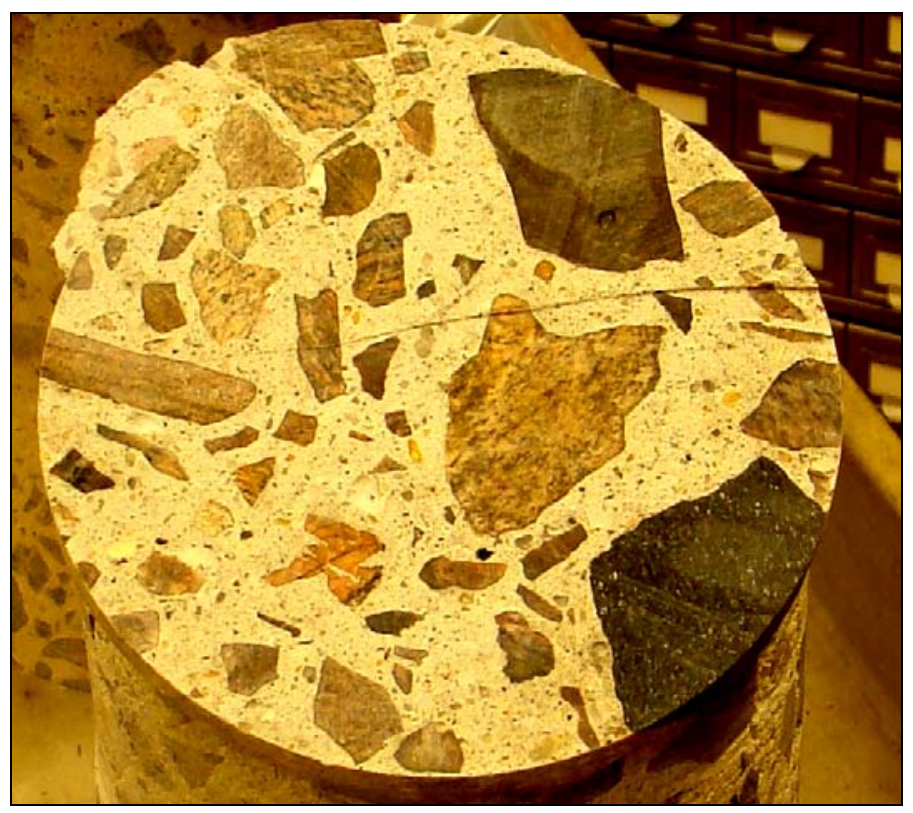

Figure 3-12. Macrograph of concrete core sample from P-reactor.

The P-reactor core was sectioned and polished for SEM/EDS analysis. The back scattered electron (BSE) micrograph in Figure 3-13 combined with the EDS analysis in Table 3-4 are focused on analyzing the large aggregate in the sample. Based on the elemental composition of the aggregate phases, fluorapatite (i.e., $\left.\mathrm{Ca}_{5}\left(\mathrm{PO}_{4}\right)_{3} \mathrm{~F}\right)$, potassium feldspar (i.e., $\mathrm{KAlSi}_{3} \mathrm{O}_{8}$ ), and plagioclase feldspar (i.e., (Na, Ca) $\mathrm{AlSi}_{3} \mathrm{O}_{8}$ ) are the primary minerals present. This is consistent with granitic aggregates used in local structural concrete.

The BSE micrograph in Figure 3-14 and the EDS results in Table 3-5 analyze the small aggregate as well as the cement phase in the cores. The results show that the small aggregate is primarily silica-quartz and cement paste mixed with fly ash. 


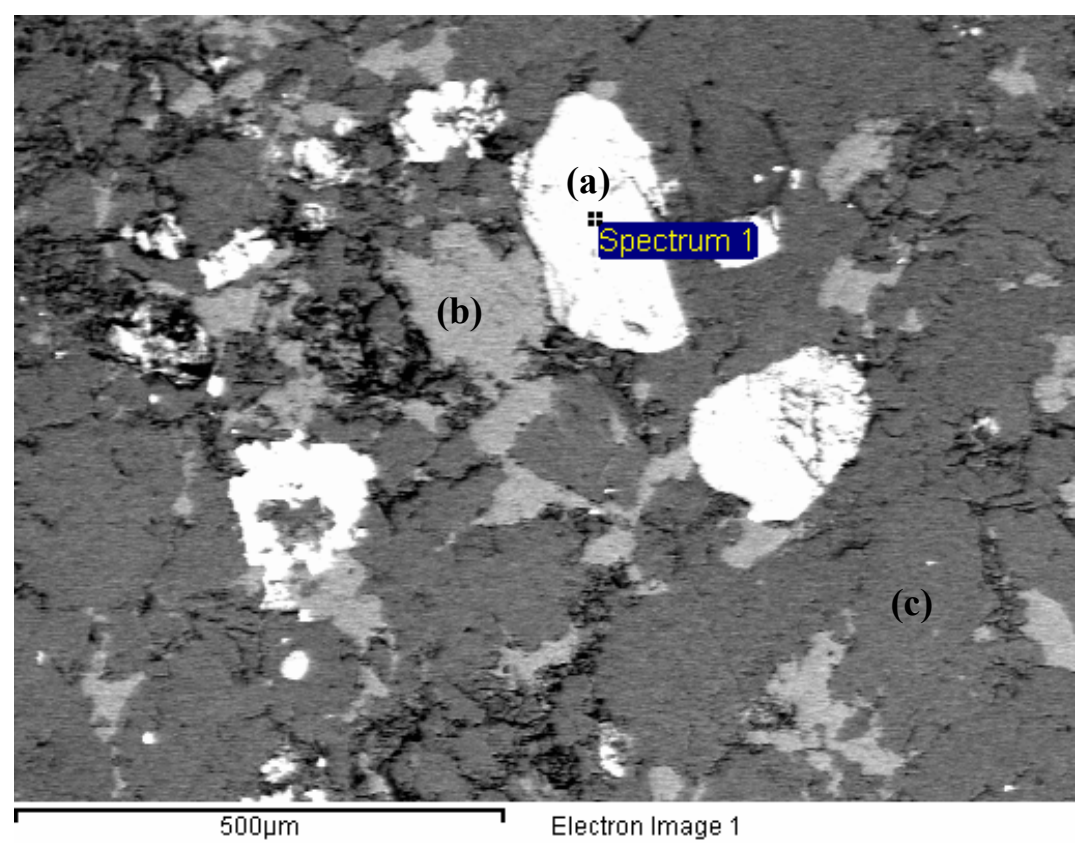

Figure 3-13. BSE Micrograph for granite aggregate in P-reactor concrete showing compositions consistent with (a) fluorapatite, (b) potassium feldspar, and (c) plagioclase feldspar.

Table 3-4. EDS results from SEM images in Figure 3-13.

\begin{tabular}{|c|c|c|c|c|c||}
\hline \multicolumn{2}{|c|}{ Spot a } & \multicolumn{2}{c|}{ Spot b } & \multicolumn{2}{c|}{ Spot c } \\
\hline Element & wt\% & Element & wt\% & Element & wt\% \\
\hline \hline $\mathrm{O}$ & 30.13 & $\mathrm{O}$ & 37.16 & $\mathrm{O}$ & 39.47 \\
\hline $\mathrm{F}$ & 4.36 & $\mathrm{Al}$ & 10.30 & $\mathrm{Na}$ & 8.58 \\
\hline $\mathrm{P}$ & 21.27 & $\mathrm{Si}$ & 36.44 & $\mathrm{Al}$ & 11.31 \\
\hline $\mathrm{Ca}$ & 44.24 & $\mathrm{~K}$ & 16.11 & $\mathrm{Si}$ & 40.64 \\
\hline Total & 100.00 & Total & 100.00 & Total & 100.00 \\
\hline
\end{tabular}




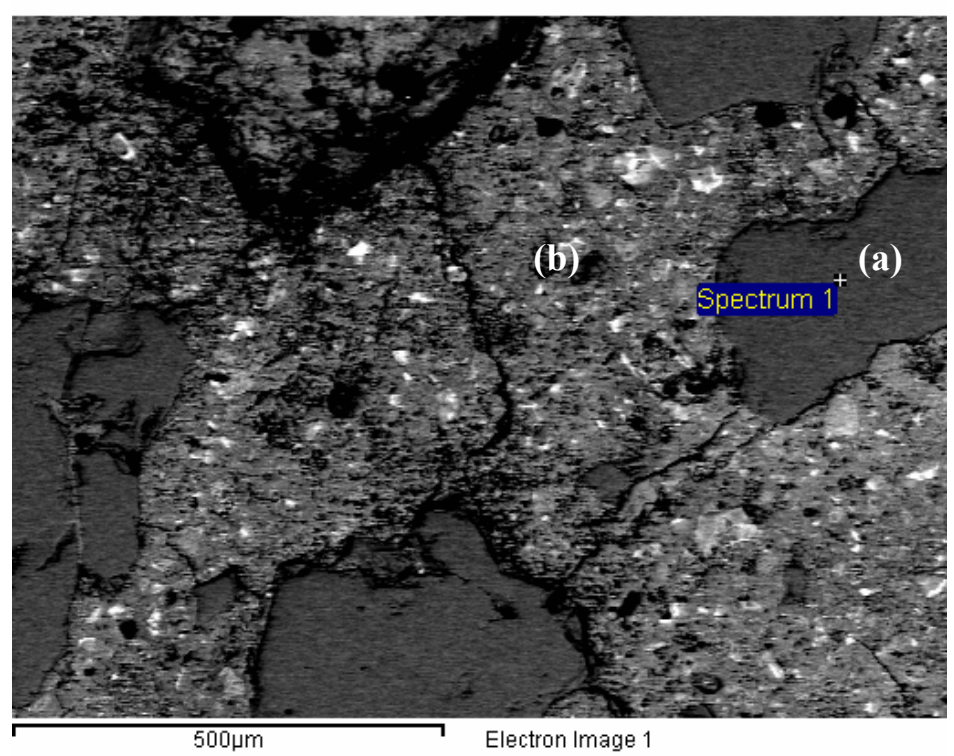

Figure 3-14. BSE micrograph for (a) small aggregate and (b) cement phase in P-reactor Concrete.

Table 3-5. EDS results from SEM images in Figure 3-14 showing (a) silica-quartz and (b) cement paste mixed with fly ash.

\begin{tabular}{|c|c|c|c||}
\hline \multicolumn{2}{|c|}{ Spot A } & \multicolumn{2}{c|}{ Spot B } \\
\hline Element & $\mathbf{w t} \%$ & Element & $\mathbf{w t \%}$ \\
\hline \hline $\mathrm{O}$ & 43.56 & $\mathrm{O}$ & 43.81 \\
\hline $\mathrm{Si}$ & 56.44 & $\mathrm{Al}$ & 3.48 \\
\hline-- & -- & $\mathrm{Si}$ & 14.63 \\
\hline-- & -- & $\mathrm{Ca}$ & 35.88 \\
\hline-- & -- & $\mathrm{Fe}$ & 2.21 \\
\hline Total & 100.00 & Total & 100.00 \\
\hline
\end{tabular}

X-ray diffraction (XRD) was conducted on select samples from P-reactor to observe which phases are present in the cement paste and aggregates. Figure 3-15 shows a sample from an exterior section of concrete and Figure 3-16 shows a sample from a carbonated layer close to the interior surface. The presence of calcite $\left(\mathrm{CaCO}_{3}\right)$ is noted in both scans but is has a greater intensity in Figure 3-16, indicating a larger volume fraction. In addition, the portlandite phase $\left(\mathrm{Ca}(\mathrm{OH})_{2}\right)$ is absent from the scan in Figure 3-16, suggesting the portlandite material has been consumed by the formation of calcite. Silica $\left(\mathrm{SiO}_{2}\right)$ is the prominent phase in both scans and is expected due to its concentration in both large and small aggregates. Other phases prominent in granite (e.g., albite and microcline) are also present in both scans. Also noted from Figure 3-15 is the minor presence of ettringite, which occurs in minute quantities in hydrated portland cements. Its formation in concrete can be a deleterious if it forms due to sulfate attack. Its formation in hardened concrete gives rise to severe degradation due to the large volume change associated with this transformation. 


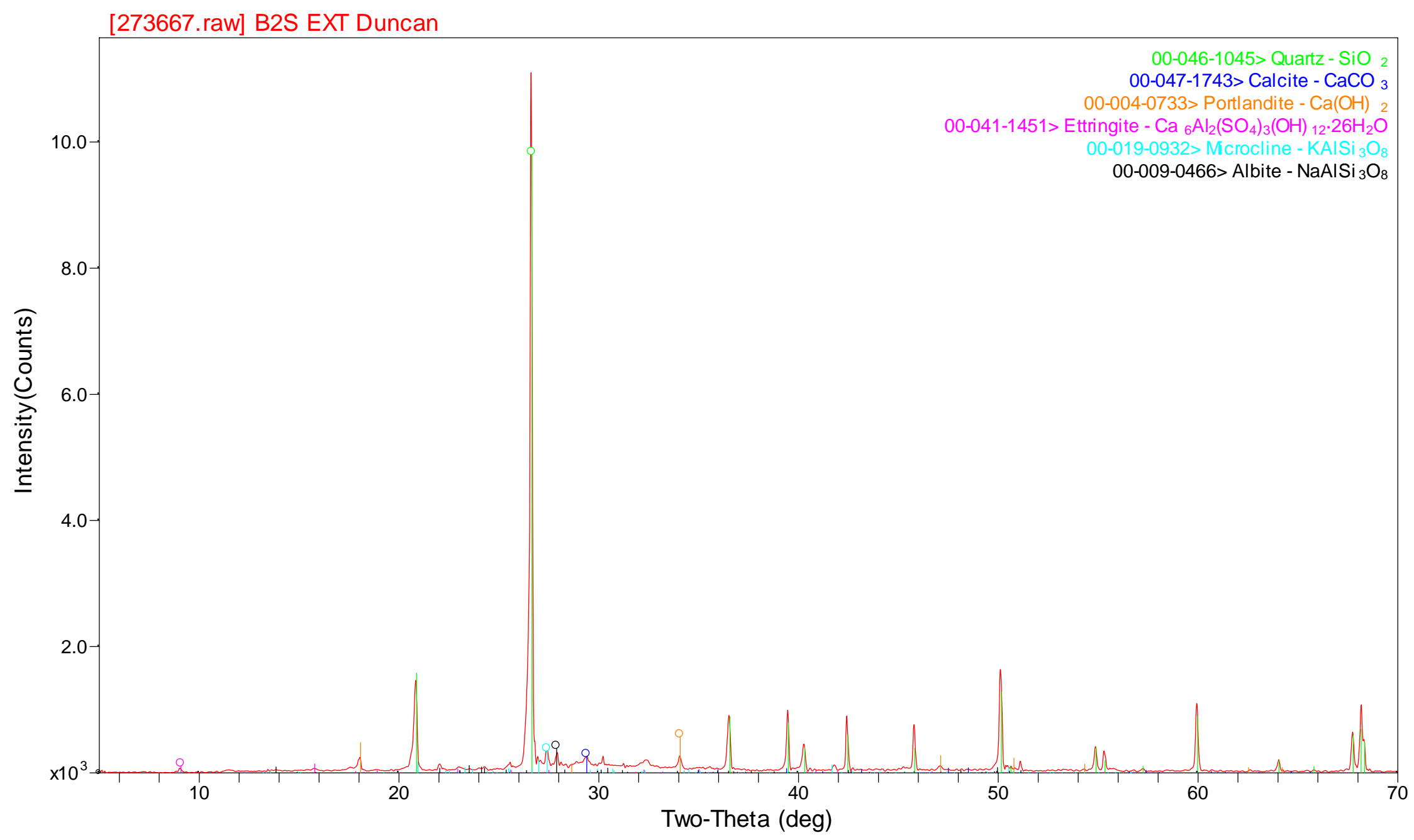

Figure 3-15. XRD scan of pulverized concrete near exterior surface from P-reactor 


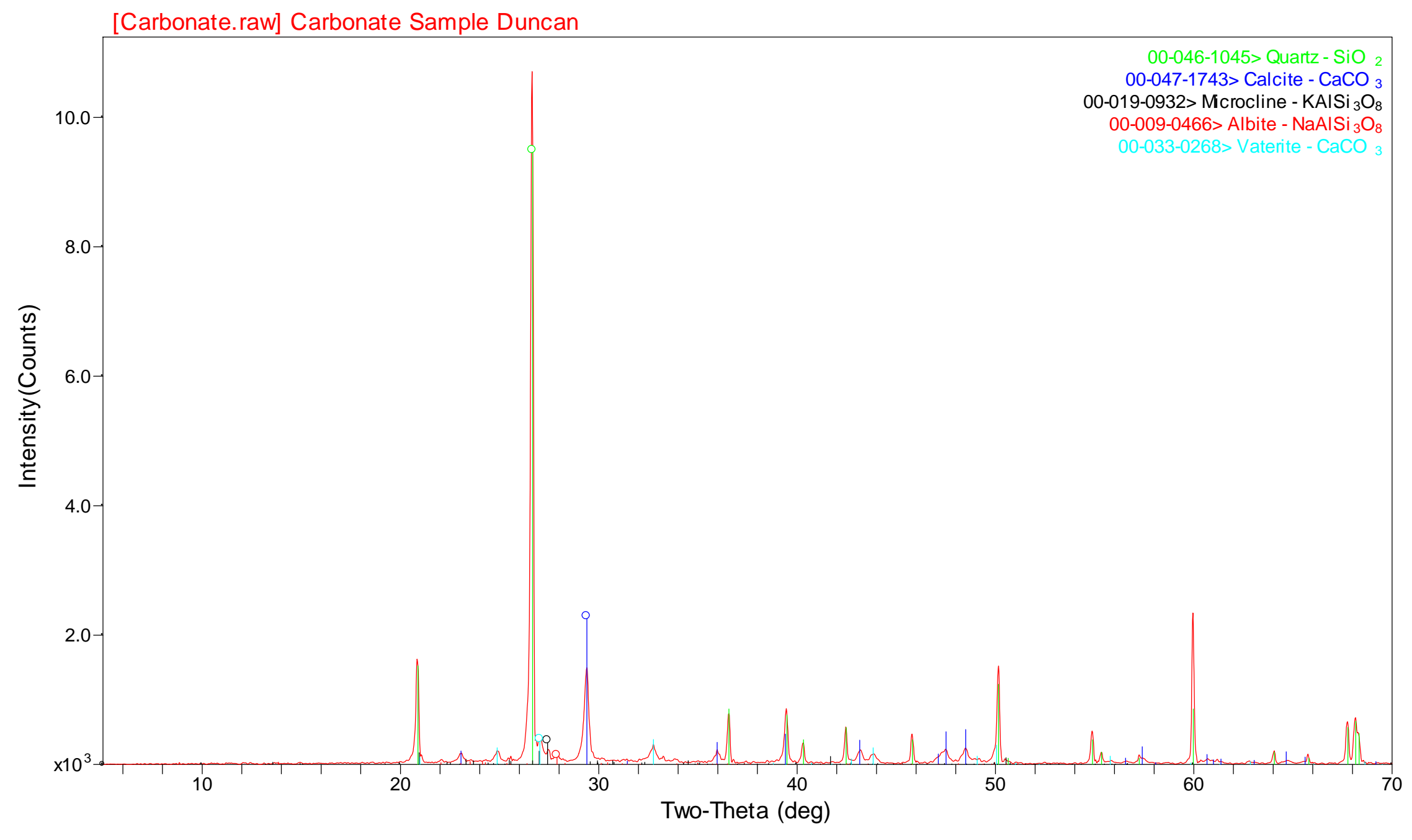

Figure 3-16. XRD scan of pulverized concrete from P-reactor near interior surface. 


\section{4 $\underline{\text { Mechanical Properties }}$}

The cores were taken in accordance with ASTM C42: Standard Test Method for Obtaining and Testing Drilled Cores and Sawed Beams of Concrete. ${ }^{11}$ Concrete cylinders were sectioned perpendicular to the coring axis and capped with a sulfur-based, silica-filled capping compound to ensure even parallel loading faces. The tests were performed in compliance to ASTM C 39 Test Method for Compressive Strength of Cylindrical Concrete Specimens. ${ }^{12}$ The loading rate was between 30 and $38 \mathrm{psi} / \mathrm{s}$ and the aspect ratio of each specimen was equal to 2.0. Specimens \#3 and \#96 were 5.6" diameter and it was difficult to obtain defect free cylinders from the core sample. Hence, the aspect ratio was slightly below two for these specimens (1.8). As shown in Figure 3-17, the actual compressive strength of each specimen exceeds the minimum acceptable 28 day breaking strength by a factor of almost 2. Hence, the design stress (2500 psi) is still exceeded 60 years after the building was built. Therefore, any degradation that has occurred thus far is insignificant with respect to the structural integrity of the concrete.

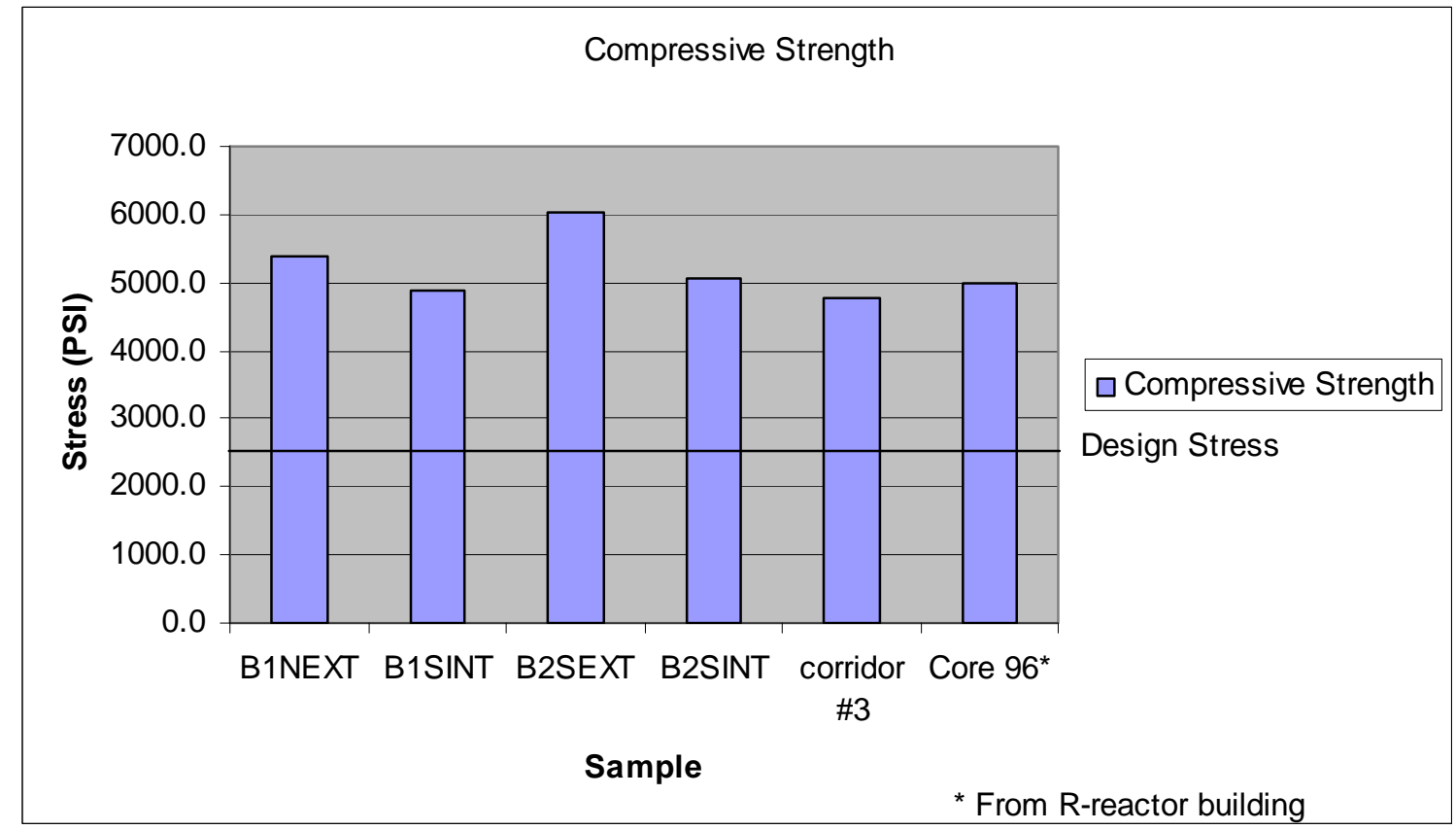

Figure 3-17. Compressive strength of concrete cores removed from Reactor buildings at SRS (all cores from P-reactor except \#96). 
SRNL-STI-2010-00729

Revision 0

\subsection{Conclusions}

Concrete blocks (six 2 to 5 ton blocks) removed from the outer wall of the P Reactor Building were transferred to SRNL as the first source for concrete cores. The cores were sectioned and evaluated using microscopy, XRD, IC and thermal analysis. Scanning electron microscopy shows that the aggregate and cement phases present in the concrete are consistent with the mix design and no degradation mechanisms are evident at the aggregate-cement interfaces. Samples of the cores were digested and analyzed for chloride ingress as well as sulfate attack. The concentrations of chloride and sulfate ions did not exceed the limits of the mix design and there is no indication of the any degradation due to these mechanisms.

Thermal analysis on samples taken along the longitudinal axis of the cores show that there is a 1 inch, fully carbonated layer present in the interior wall of the reactor building and a negligible carbonation layer in the exterior wall. This is understood due to the enhanced carbonation rates known to occur in concrete subjected to indoor exposures. A mixed layer of carbonate and portlandite is present to 2.5 inches on the interior side and 1.5 inches on the exterior side. This was confirmed by applying a $1 \%$ phenolphthalein solution to the cores as well as by analyzing pulverized samples using $\mathrm{XRD}$. Once the carbonation layer reaches the rebar that is approximately 3 inches into the concrete wall, the steel is susceptible to corrosion. However, based on the growth rate of the carbonation layer, it will not reach the steel rebar for at least another 125 years and will be structurally sound for several hundred years beyond this. Based on the measurements of the carbonation front advance in this study and the previous prediction of the time to structural collapse ${ }^{1}$ the length of time before water intrusion is expected into the process room of P-reactor is 425-675 years. 


\subsection{Recommendations, Path Forward or Future Work}

Although the 2008 evaluation identifies vegetative growth as the controlling degradation mechanism of P-Reactor, ${ }^{1}$ the cores for this study are from a wall that had no vegetative growth present and therefore it was not considered in this report. However, future testing of the cores from $\mathrm{P} \& \mathrm{R}$ reactors as well as other ISD buildings should be evaluated for the presence of vegetative growth since it severely limits the durability of the structure. A petrography study should also be conducted on thin sections of the cores to more accurately determine the integrity of the aggregates in the concrete. This would determine if there are any damaging reactions taking place at the aggregate-cement interface that is not easily determined by inspecting chunks of the concrete. In addition, corrosion studies of the rebar in the concrete should be conducted to determine the corrosion rate once the carbonation layer reaches the steel rebar. SRNL has received cores from R-reactor but at the time of this report they have not yet been analyzed. Future work on these cores will include all the analyses described in this report. 
SRNL-STI-2010-00729

Revision 0

\subsection{References}

1. $\quad$ Carey, S.A., "Long Term Assessment of 105-P Structure for In-Situ D\&D Alternatives," Savannah River Site, Aiken, SC, T-CLC-P-00004, August 2008.

2. Specification 3019, Building Materials and Plumbing, Revision 28, E.I.duPont de Nemours \& Company.

3. Petrographic Investigation of Concrete from Building 221-H, Savannah River Site, U.S. Army Core of Engineers, 1996.

4. "Manual for Inspecting, Evaluating, and Diagnosing Corrosion in Reinforced Concrete Structures," Ibero-American Program Science and Technology for Development, (2000).

5. Villain, G., Thiery, M., and Platret, G., "Measurement Methods of Carbonation Profiles in Concrete: Thermogravimetry, Chemical Analysis, and Gammadensimetry," Cement and Concrete Research, 37, 1182-92 (2007).

6. Alarcon-Ruiz, L., Platret, G., Massieu, E., and Ehrlacher, A., "The Use of Thermal Analysis in Assessing the Effect of Temperature on a Cement Paste," Cement and Concrete Research, 35, 609-13 (2005).

7. Zurbriggen, R., Investigation of the Segregation Behavior of Different Mortar Constituents with TGA/SDTA, Mettler-Toledo GmbH Analytical.

8. Mehta, P.K. and Monteiro, P.J.M., Concrete: Microstructure, Properties, and Materials, Third ed. McGraw-HIll, 2006.

9. Walton, J.C., "Models for Estimation of Service Life of Concrete Barriers in Low-Level Radioactive Waste Disposal," NUREG/CR-5542, (1990).

10. Papadakis, V.G., "Reaction Engineering Approach to the Problem of Concrete Carbonation," AIChE Journal, 35, [10] 1639 (1989).

11. Standard Test Method for Obtaining and Testing Drilled Cores and Sawed Beams of Concrete, ASTM C 42.

12. Test Method for Compressive Strength of Cylindrical Concrete Specimens, ASTM C 39. 


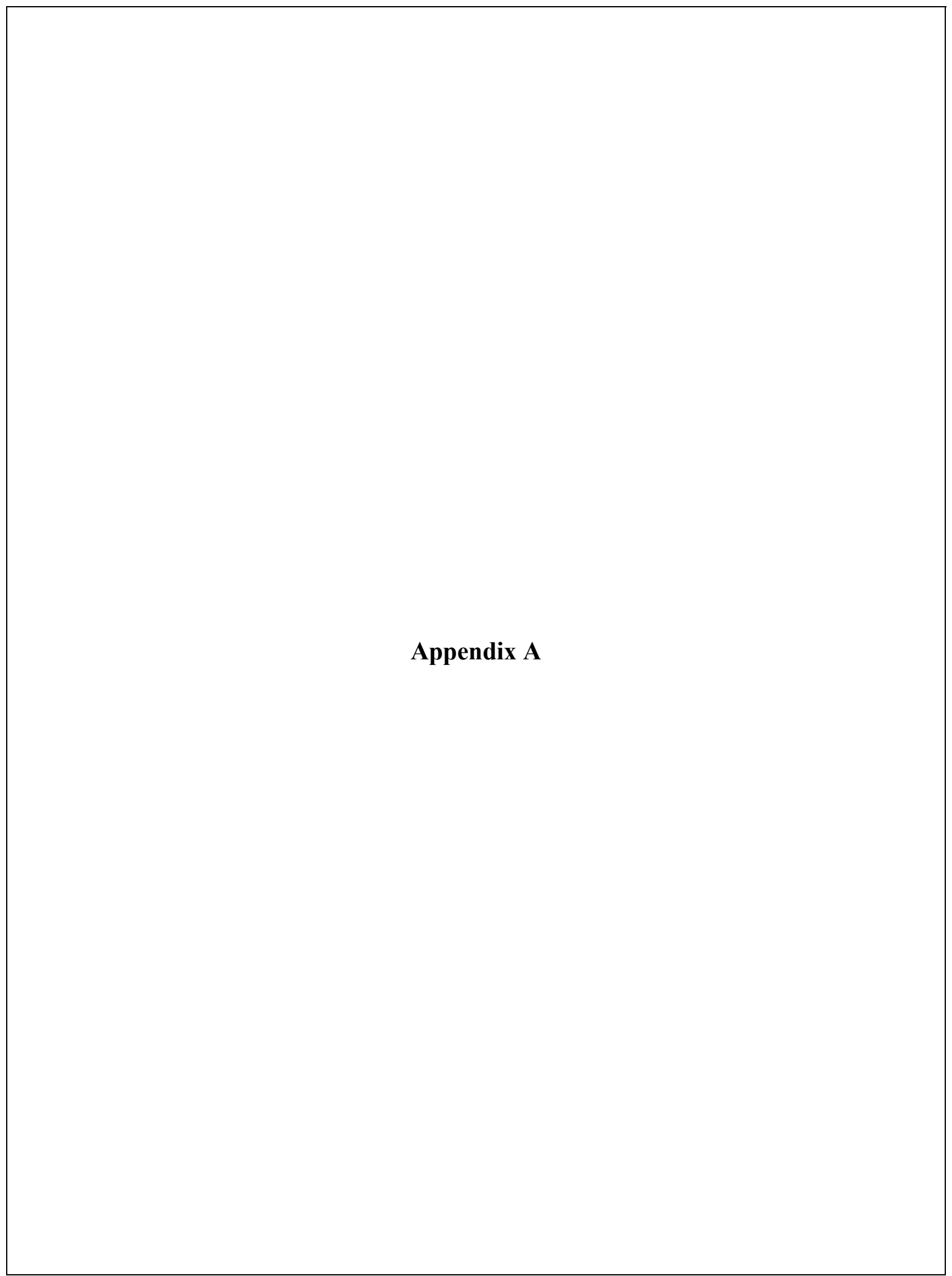


In addition to the cores taken from the interior and exterior walls of P-reactor and analyzed using TGA and DSC as discussed in section 3.1.2, cores were taken from Core 57 (R-reactor) and Corridor \#4 (P-Reactor). Figure A-1 and Figure A-2 are the results from Core 57 and Figure A-3 and Figure A-4 are from Corridor \#4. The results from Core 57 indicate that, to date, there is no carbonation present in the wall of R-reactor. The results from Corridor \#4 confirm the presence of a carbonation layer as shown in section 3.1.2 for the interior core sample taken from P-reactor.

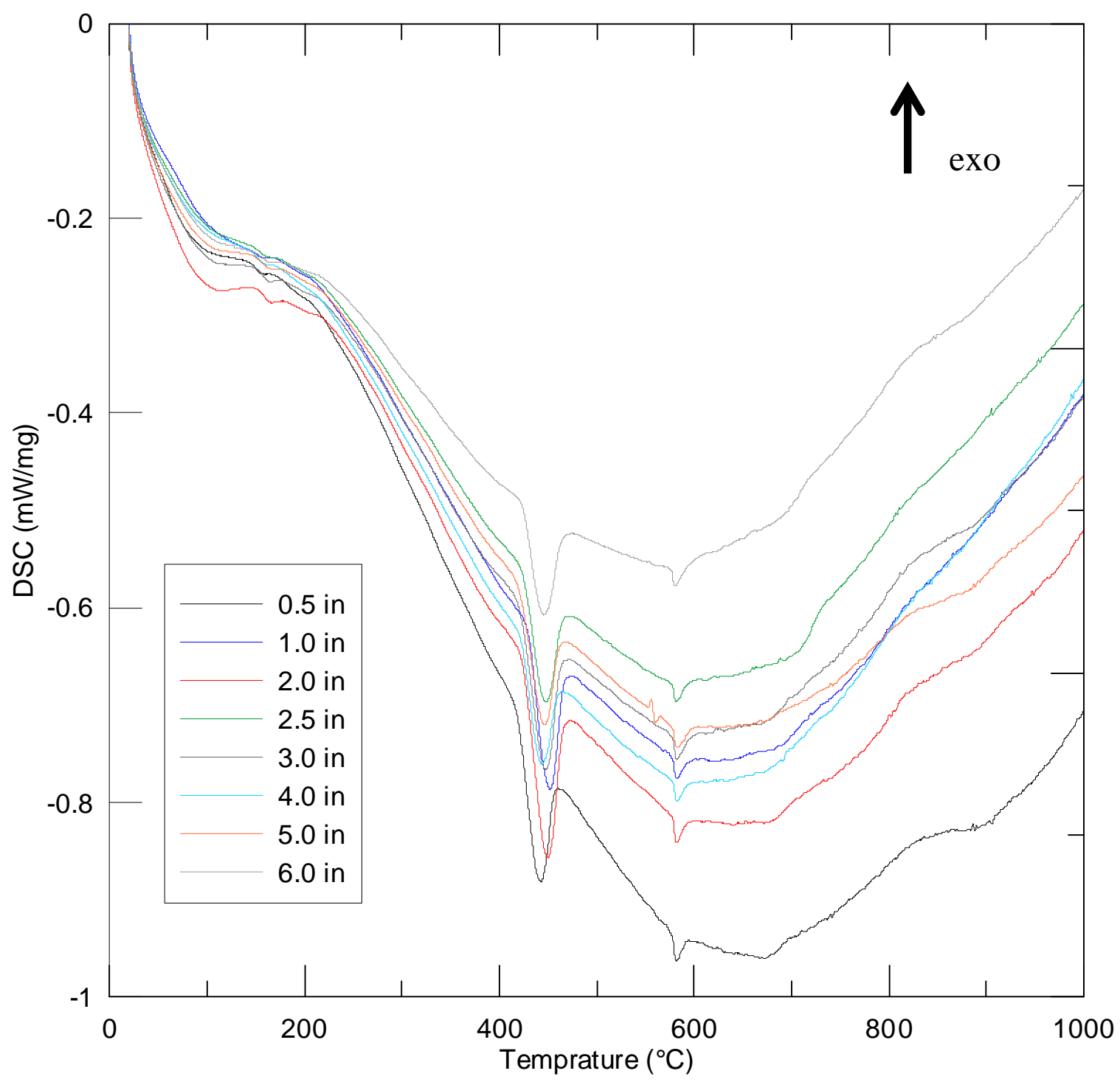

Figure A-1. DSC Curve for depth samples taken from core 57 taken from R-reactor. 
SRNL-STI-2010-00729

Revision 0

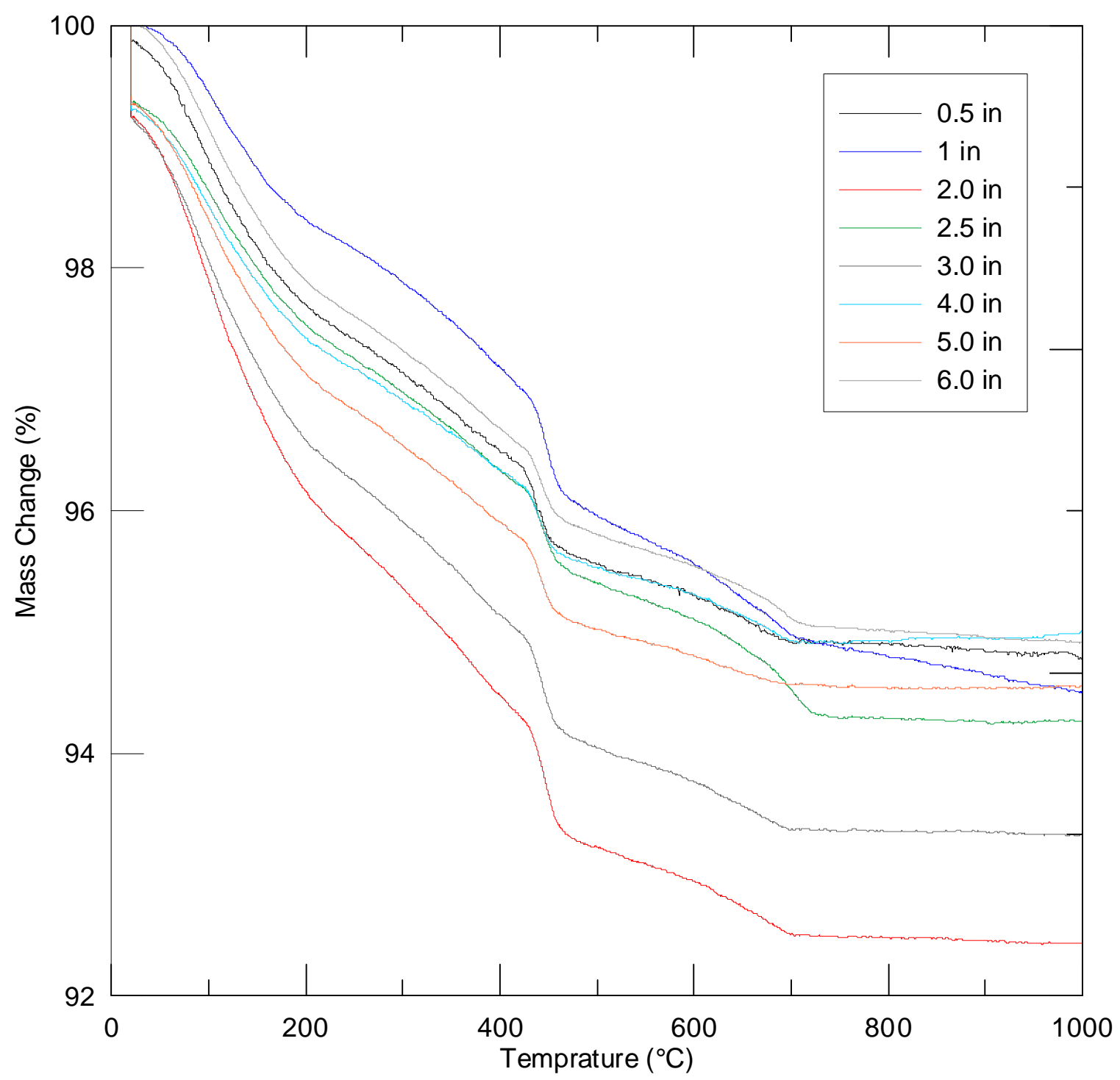

Figure A-2. TG curve for depth samples from core 57 taken from R-reactor. 


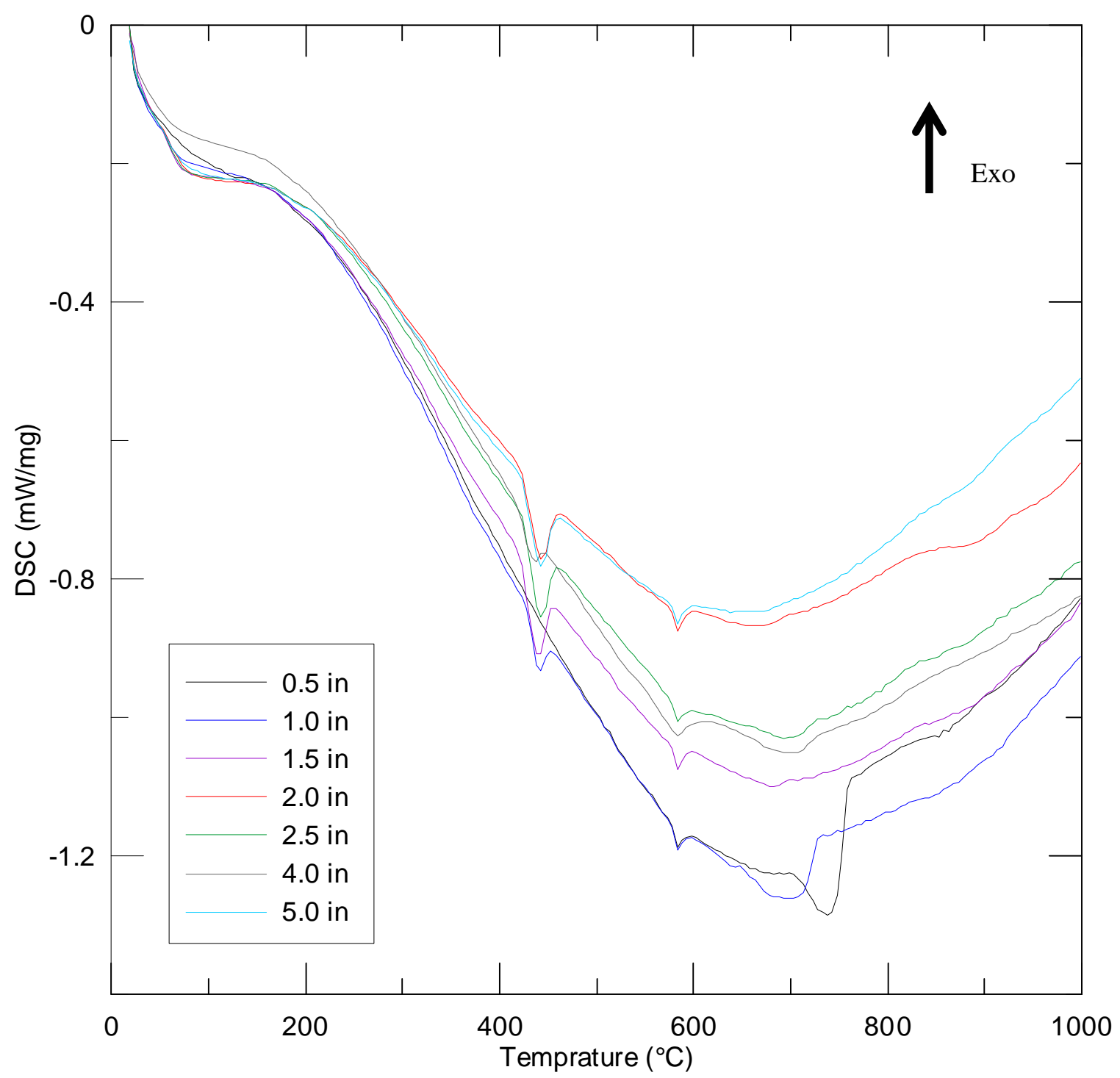

Figure A-3. DSC curve for depth samples from Corridor \#4 in P-reactor. 


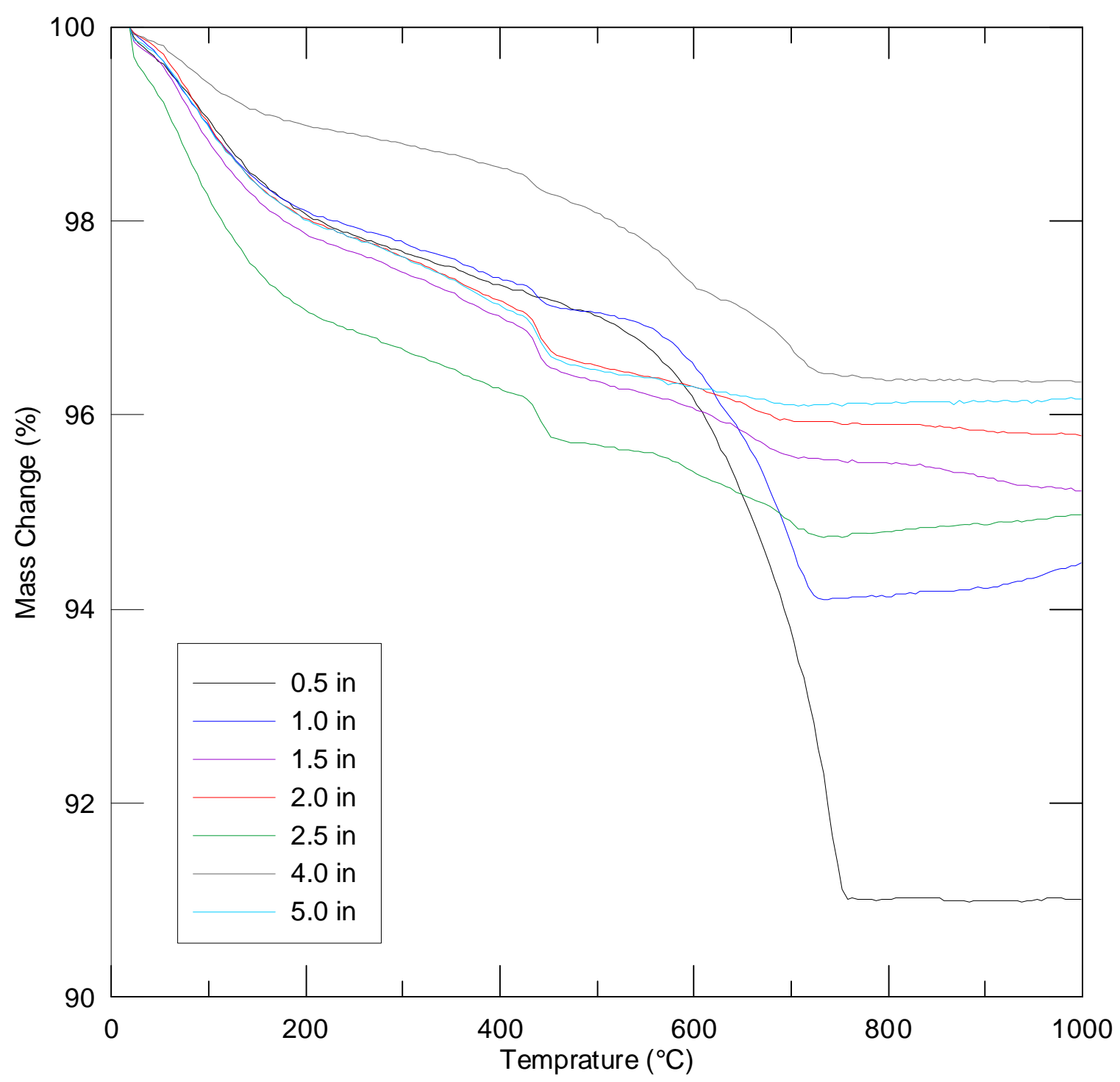

Figure A-4. TG curve for depth samples from Corridor \#4 in P-reactor. 